\title{
Information Models for Forecasting Nonlinear Economic Dynamics in the Digital Era
}

\author{
Askar Akaev, Viktor Sadovnichiy \\ Moscow State University, Moscow, Russia \\ Email: askarakaev@mail.ru
}

How to cite this paper: Akaev, A. and Sadovnichiy, V. (2021) Information Models for Forecasting Nonlinear Economic Dynamics in the Digital Era. Applied Mathematics, 12, 171-208. https://doi.org/10.4236/am.2021.123012

Received: January 21, 2021

Accepted: March 16, 2021

Published: March 19, 2021

Copyright (c) 2021 by author(s) and Scientific Research Publishing Inc. This work is licensed under the Creative Commons Attribution International License (CC BY 4.0).

http://creativecommons.org/licenses/by/4.0/

(c) (i) Open Access

\begin{abstract}
The aim of this study was to develop an adequate mathematical model for long-term forecasting of technological progress and economic growth in the digital age (2020-2050). In addition, the task was to develop a model for forecast calculations of labor productivity in the symbiosis of "man + intelligent machine", where an intelligent machine (IM) is understood as a computer or robot equipped with elements of artificial intelligence (AI), as well as in the digital economy as a whole. In the course of the study, it was shown that in order to implement its goals the Schumpeter-Kondratiev innovation and cycle theory on forming long waves (LW) of economic development influenced by a powerful cluster of economic technologies engendered by industrial revolutions is most appropriate for a long-term forecasting of technological progress and economic growth. The Solow neoclassical model of economic growth, synchronized with LW, gives the opportunity to forecast economic dynamics of technologically advanced countries with a greater precision up to 30 years, the time which correlates with the continuation of LW. In the information and digital age, the key role among the main factors of growth (capital, labour and technological progress) is played by the latter. The authors have developed an information model which allows for forecasting technological progress basing on growth rates of endogenous technological information in economics. The main regimes of producing technological information, corresponding to the eras of information and digital economies, are given in the article, as well as the Lagrangians that engender them. The model is verified on the example of the $5^{\text {th }}$ information LW for the US economy (1982-2018) and it has had highly accurate approximation for both technological progress and economic growth. A number of new results were obtained using the developed information models for forecasting technological progress. The forecasting trajectory of economic growth of developed countries (on the example of the USA) on the upward stage of the $6^{\text {th }}$ LW (2018-2042), engendered by the digital technologies of the $4^{\text {th }}$ Industrial Revolution is given. It is also dem-
\end{abstract}


onstrated that the symbiosis of human and intelligent machine (IM) is the driving force in the digital economy, where man plays the leading role organizing effective and efficient mutual work. Authors suggest a mathematical model for calculating labour productivity in the digital economy, where the symbiosis of "human + IM" is widely used. The calculations carried out with the help of the model show: 1) the symbiosis of "human + IM" from the very beginning lets to realize the possibilities of increasing work performance in the economy with the help of digital technologies; 2) the largest labour productivity is achieved in the symbiosis of "human + IM", where man labour prevails, and the lowest labour productivity is seen where the largest part of the work is performed by IM; 3) developed countries may achieve labour productivity of $3 \%$ per year by the mid-2020s, which has all the chances to stay up to the 2040 s.

\section{Keywords}

The Schumpeter-Kondratiev Innovation and Cycle Theory of Economic Development, The Solow Neoclassical Model of Economic Growth, Information Model of Technological Progress, Symbiosis of "Human + Intelligent Machine", Labour Productivity in the Symbiosis of "Human + IM" and the Digital Economy

\section{Introduction}

The widespread use of digital technologies has led to increasing attention being paid to issues such as the relationship between the digital economy and the development of new business models [1], the role of new breakthrough technologies in changing economic relations [2], and reducing the main costs associated with digital economic activity [3]. As a first step in understanding the nature of digital transformation, it is proposed to distinguish between the "digital sector" and the increasingly expanding trend of digitalization of the modern economy, which is often called the" digital economy" [4]. New approaches to classifying sectors are being formed depending on the degree of their transition to digital technologies [5]. A true "digital economy" is now defined as "a part of the economic output generated exclusively or predominantly by digital technologies and business models based on digital goods or services" [6]. Since digital technologies cause accelerated changes in the organization of labor, proposals for new social approaches to the development and use of innovative models in the digital economy are of great interest [7]. One of the most recent publications [8] addresses the issues of creating a unified system for measuring the digital economy, including a set of existing indicators for measuring jobs, employee skills, as well as the infrastructure for implementing digital technologies. However, we did not find any work on modeling and forecasting the dynamics of the digital economy for the future, which is necessary for developing a long-term development strategy. 
It should also be noted that certain aspects of the digital economy are evaluated differently by the expert community. Some believe that the future belongs to robots and people working together, as automation gives people the opportunity to focus on more skilled and highly paid tasks [9]. However, measured productivity growth in the US decreased by half over the past decade, whereas the real income of most Americans has not changed since the 1990s. In this regard, the authors of the study [10] believe that the impressive capabilities of intelligent machines will not be fully realized until special additional innovations are developed and implemented. That is why it is proposed to solve the discrepancy between the skill requirements for working with new technologies and the possibility of implementing automation with elements of artificial intelligence at the expense of other technologies that increase productivity [11]. Unfortunately, there is still no model for calculating labor productivity in the symbiosis of "man + intelligent machine", in order to evaluate the effectiveness of the methods of organizing labor in the digital economy proposed in the aforementioned studies. As for the impact of IT on economic growth and the growth of aggregate factor productivity, it should be noted that such estimates already exist [12]. There is also a study on quantitative impact of IT on economic growth based on data from 39 African countries for 2012-2016 [13]. However, models for calculating and predicting growth in the digital age do not yet exist.

As can be seen from the brief review of the above-stated studies, many problematic issues of digital economy formation have already been investigated and quite interesting results, which answer these questions, have been obtained. In our work, we aimed to supplement and expand the existing methods of studying the digital economy, in particular on the basis of the information model developed by us [14], which allows us to predict technological progress on a longterm basis, using the growth rate of endogenous technological information in the economy. The article presents the main modes of production of technological information corresponding to the epochs of informatization and digitalization of the economy, as well as the Lagrangians that generate them. The model was tested (verified) on the example of the 5th information LW for the US economy (1982-2018) and showed a very high accuracy of approximation both for technological progress and for calculating economic growth. Using the developed model, an example of calculating the forecast trajectory of economic growth for the United States at the stage of the digital economy formation (2018-2042), as well as a forecast calculation of labor productivity in the symbiosis of "man + intelligent machine", are given.

\section{The Schumpeter-Kondratiev Innovation and Cycle Theory of Economic Development}

The crisis of world financial and economic system in 2008-2009, which led to the Great Recession in the USA and decrease in the majority of developed world economies, followed by the long global depression, lasting for almost 10 years, reminded the politicians, economists and businessmen that market economy 
had an uneven, unstable and cyclic character of development. Crises and depression are logical, and the governments must forecast them and try to mitigate them. In such periods of cyclic crisis recessions and depressions in the world economy the scholars tend to turn to the Kondratiev long wave theory (LW) of economic development [15], lasting for 30 - 40 years in the modern era. It was so in the period of the Great Depression of the 1930s, then it happened in the 1970s and 1980s during the structural crisis of the world economy, when profound works on the LW theory were created. The compound analysis of these works can be found in the research [16]. We have developed a complete closed mathematical model in the work [17] to describe and calculate the Kondratiev long wave of economic development, which allows us to forecast all major economic variables with a long-term perspective up to 30 years, which corresponds to the length of LW. We can say that nowadays there exists a satisfactory and comprehensive explanation of the LW theory or long economic cycles.

Kondratiev stated that long economic cycles have an endogenous character, i.e. they are internally characteristic of capital economy. It is important to state that he was the first to understand that wavy cyclic movements of the economy deviate from a balance which the capitalist economy tries to preserve. Consequently, most of the time a healthy dynamic economy develops in imbalance, while the classical economic theory stated the contrary. Kondratiev himself identified first (1780/90-1845/51), second (1845/51-1890/96) and third (1890/96-1940/46) long economic cycles. Besides, at the beginning of the 1920s he made an assumption that a cyclic crisis should take place at the end of the 1920s followed by the depression, which indeed happened in 1929 and the 1930s. Another great economist of the $20^{\text {th }}$ century, Joseph Schumpeter, continued Kondratiev's study of LW and developed an innovation theory of long waves integrating it in his general innovation theory of economic development [18]. Schumpeter saw cycles as the direct consequence of innovative processes determined by technological progress, and, as well as Kondratiev, he believed that the cyclical movement the output was a deviation from the balance.

It should be mentioned that Schumpeter highlighted that the main driving force of the capitalist economy was innovations and entrepreneurship, not capital per se, as many economists of that time thought. Schumpeter stated that capital is useless and powerless to cause economic growth without innovations and initiative, will and perseverance of the entrepreneur. Schumpeter believed that spontaneous "blobs" of innovation by forming large clusters, caused radical changes in economy, taking it away from the original balanced trajectory only seen in the periods of stagnation. Moreover, the system never returns to the original balance. A new cycle begins at the end of another depression at a new level of balance.

According to Schumpeter, the change in balance levels determine the longterm trajectory of economic development, during which economic system is in a dynamic, not a stationary, balance. Both Kondratiev and Schumpeter believed that there existed three types of balance, and, consequently, three oscillating 
movements, which consist of short Kitchin cycles ( 3 - 5 years), provoked by oscillations of inventories; medium industrial Juglar cycles (7 - 11 years) and long Kondratiev cycles (30 - 40 years). These three waves overlap the trend trajectory of economic growth and, according to Schumpeter, their superposition shows the general state of economic development at every moment [18].

Schumpeter was the first to assume that innovations appear unevenly in time, and then spontaneously unite in clusters of innovations. He distinguished basic and ameliorative innovations. He highlighted the key role of basic innovations in the cyclic dynamics of long waves of economic development, seeing them as the main driving force of the capital economy. In fact, he predicted the 4th afterwar LW (1946-1982) generated by a large cluster of epoch-making basic innovations, including computers, electronics, televisions, jet and rocket engines as well as nuclear energy. Since the long economic cycle concept plays a highly important role in the Schumpeter innovative theory of economic development, and taking into account the fact that Schumpeter himself saw it as a cornerstone of his theory, we decided to call the latter "the Schumpeter-Kondratiev innovation and cycle theory of economic development."

The Schumpeter-Kondratiev innovation and cycle theory of economic development is valuable because it suggests an effective mechanism to overcome the global cyclic crisis followed by the depression through "the launch and comprehensive stimulating of storm of the new generation of highly effective basic technological innovations" [19], aiming at substitution of outdated industrial technologies and forms of organizing production. It is also important that this theory shows in a certain way the period of crises and depressions, and it also has an innovative paradigm for forecasting the beginning of a new cycle [20].

The success of the Schumpeter-Kondratiev theory was already evident in the 1980s. Firstly, it should be noted that Mensch then predicted the appearance of a cyclic structural crisis of the world economy at the end of the 1970s in its beginning. Secondly, he accurately pointed out the feature characteristic of the forthcoming crisis-"stagflation", which meant that economic stagnation would be coupled with rise in prices, i.e. inflation, and not their decrease as it was before. Thirdly, he clarified that under such circumstances monetary and credit policy could not help in resolving the problem of overcoming the crisis [19]. Mensch and other adherents to the Schumpeter-Kondratiev theory suggested launching the process of mastering the basic innovations of a new technological paradigm based on the achievements of microelectronics and information technology.

The Schumpeter-Kondratiev innovation and cycle theory was validated during the $5^{\text {th }} \mathrm{LW}$ (1982-2018). The core for the $5^{\text {th }}$ technological paradigm was microelectronics, personal computers, information and communication technologies (ICT) and biotechnology [20]. Microprocessors and computers became widely spread and their usage turned out to be a breakthrough in goods production in each field of the economy and control of dynamic objects. It was demonstrated in the work [21] that the beginning of the $5^{\text {th }}$ long economic cycle dated back to 1982. Indeed, it was 1982 when there was a rise in the world economy, which 
then transformed into a lengthy (1982-1994) period of a stable and quite rapid economic growth with average annual rates of 3.4 percent, which ended with a slight fall in 1995. Then, economy flourished from 1996 to 2006 when labour productivity rates reached $2.8 \%$ per year and they almost twice exceeded the same figure for the previous decade (1985-1995).

Mentioned achievements could be explained by the usage of ICT and an upsurge in investments in the sphere. It explains the phenomenon of an intermittent labour productivity growth in the second half of the 1990s in developed countries. At the beginning of the $21^{\text {st }}$ century the global ICT market exceeded 1 billion US dollars. At that time the talks on the emergence of new economy"knowledge economy"-began in developed countries. However, by the mid2000s the growth of production caused by ICT stopped. According to Mensch, it meant that the $5^{\text {th }}$ long economic cycle reached its peak and it was necessary to search for innovative technologies and next generation products. In 2006-2007 there was a recession in economic growth rates in OECD countries, which meant the transfer from an upward stage of the $5^{\text {th }} \mathrm{LW}$ to a downward. Thus, 2004-2005 were the upper turning point for the $5^{\text {th }}$ LW. The continuity of the upward stage of the $5^{\text {th }}$ LW predictably constituted 22 - 24 years (1982-2006).

Less than three years had passed before a sudden world financial and economic crisis of 2008-2009 broke out, which resembled the crisis of 1929, followed by the Great Depression of the 1930s, and thus called "The Great Recession". In the work [22] we have shown that a bursting rise in prices on such highly liquid commodities as oil and gold is a forerunner of global cyclic financial and economic crises and we have also developed a nonlinear dynamic model for forecasting the onset of the crisis. With the help of this model we successfully predicted the date of the second wave of the global financial crisis of August 2011 nine months before it actually took place with an error of only two weeks and it showed that the crisis of 2008-2009 could have also been predicted beforehand.

Then, with the help of the Hirooka innovation paradigm [20] we also described the trajectory of developing basic technologies of the $6^{\text {th }}$ technological paradigm and predicted the beginning of the $6^{\text {th }}$ LW-2017-2018. Next, we calculated economic potential of NBIC-technologies [23]. Since NBIC-technologies are mutually convergent, a significant synergetic effect is achieved due to their cooperative action, and this effect is to accelerate the rates of technological progress in developed countries up to $3 \%$ and higher by 2030 , which is much better than the same rate during the rise of the $5^{\text {th }}$ long economic cycle (1982-1994), which was $2.3 \%$. Consequently, basic technologies of the $6^{\text {th }}$ technological paradigm will be able to ensure record rates of economic growth close to those back in the 1950-1960s.

Indeed, as was predicted in the Schumpeter-Kondratiev theory, in 2017 there was a simultaneous growth of leading world economies. According to the IMF, by the end of 2017 all eight world economies (the USA, China, Japan, Germany, India, Russia, France and the UK) increased by over 1.5\% [IMF, 2018]. All the 
world economy also increased by 3.8\% in 2017 against 3.2\% in 2016. In 2018 a simultaneous growth of GDP was seen in almost each of those 45 countries observed by the OECD. The IMF points out that such an event has occurred only twice over the past 40 years and adds that previously such periods of a simultaneous growth lasted, as a rule, for several years. For example, the world economy grew at a rate of 4\% annually in 1984-1989 and 2004-2007, i.e. at the beginning of the development and on the peak of the upward stage of the $5^{\text {th }} \mathrm{LW}$. It is evident that since 2018 we have observed the development of the $6^{\text {th }}$ LW, which will last for about thirty years.

The question arises: will the current simultaneous growth of developed world economies be stable in the medium term? Kondratiev and Schumpeter noted in their classical works that the economic growth at the beginning of the development at the upward stage of the long economic cycle is subjected to various risks, which make it unstable, and recommended that the governments assist entrepreneurs with overcoming such risks. The main risks that the current stable economic growth faces are: a large scope of a total debt of governments, households, corporate and financial sectors; aggravating gap between the real economy and the financial sphere; accelerating growth of the excessive income inequality; an acute shortage of consumer demand; instability of the financial system and sharp increase in protectionism from developed countries, transformed in trade wars, and increased environmental threats. It is possible to solve all these problems only globally, for instance, at the G20 summits. However, contrary to the crisis years of 2008-2009, there is no spirit of global cooperation nowadays. At that time the G20 countries acted as a single whole, which played a unique role in preventing the worst consequences of the financial crisis. Now we can see trade and ideological conflicts between leading countries, which hinder constructive cooperation in the context of the G20. That is why there are reasons to believe that the development of the $6^{\text {th }} \mathrm{LW}$ will be quite unstable and may be interrupted by crisis recessions, not so lengthy and deep as "The Great Recession" of 2009.

\section{Mathematical Models for Describing and Forecasting the Dynamics of Information and Digital Economy}

To describe a long-term economic dynamics in a technologically developed country we can successfully use a classical Cobb-Douglas production function (PF) with a labour-saving technological (technical) progress [14]:

$$
Y(t)=\gamma \cdot K^{\alpha}(t) \cdot(A(t) \cdot h \cdot L(t))^{1-\alpha+\delta},
$$

where $Y(t)$ is a current national income $(G D P) ; K(t)$ is a productive capital; $L(t)$ is a number of employees in the economic sphere, $h$ is the average level of human capital; $A(t)$ is technological progress; $\alpha$ is the capital share in GDP; $\delta$ is the parameter characterizing the growing impact of production scale $(\delta>0)$; $\gamma$ is a constant normalizing index. It is explained by the fact that informationand the future digital economy-is the same high-technology economy where 
the key role for increasing the production of main factors, capital and labour, is played by ICT, digital technologies and platforms. To calculate in the retrospective area with the help of PF (1), we used the data from the following sources:

$$
Y(t) \text { and } L(t)
$$

[https://apps.bea.gov/iTable/iTable.cfm?reqid=19\&step=2\&isuri=1\&1921=servey];

$$
K(t)
$$

[https://apps.bea.gov/iTable/iTable.cfm?ReqID=10\&isuri=1\&step=1\%20\%20reqi d\%(1a) 3D10\#reqid=10\&step=1\&isuri $=1$;

$A(t)$ [https://fred.stloisfed.org/series/RTFPNAUSA632NRUG].

In PF (1) and in the time of information and digital economy capital and labour may be described with the help of traditional methods and models ([24], $\$ 2.1$. However, technological progress $A(t)$ cannot be described using traditional models ([24], ch.5) since they do not have the main factor of informational and digital economy-the speed and scope of the production of technological information. In what follows we give an account of mathematical models for calculating and forecasting the dynamics of technological progress in information and digital economy, based on (speed) rates of the production of technological information. These information models first appeared in our work [14] and were developed in the work [25]. For practical application it is better to write and use PF (1) in a tempo-based form by means of its logarithmic differentiation:

$$
q_{Y}=\alpha \cdot q_{K}+(1-\alpha+\delta) \cdot\left(q_{A}+q_{L}\right),
$$

where

$$
q_{Y}=\frac{\dot{Y}}{Y} ; \quad q_{K}=\frac{\dot{K}}{K} ; \quad q_{L}=\frac{\dot{L}}{L} ; \quad q_{A}=\frac{\dot{A}}{A} .
$$

If the functions describing the main economic variables in PF (1) are known, it is easy to find their rates of growth by using Formulas (2a). Vice versa, if the growth rates of variables are given (2a), there is no difficulty in determining variables by formulas

$$
\text { a) } Y(t)=Y_{0} \cdot \exp \left[\int_{T_{0}}^{t} q_{Y}(\tau) \mathrm{d} \tau\right] \text { or b) } A(t)=A_{0} \cdot \exp \left[\int_{T_{0}}^{t} q_{A}(\tau) \mathrm{d} \tau\right] \text {. }
$$

We should note that here and above it has concerned an average technological level $A(t)$ over the whole economy, which is clearly defined by high technological level of newly formed innovative fields of the economy. In our case these are the fields of information and digital economies.

PF (1) was verified for a number of developed countries of OECD and it turned out that it could function perfectly. For example, for the US economy from 1946 to 2018, we have received the following meanings for index $\gamma$ and parameters $\alpha$ and $\delta$ in PF (1), basing on the range of factual values of main factors ( $Y, K, A$ and $L$ ), taken from the data base (1a) in corresponding prices, and using the method of least squares: 


$$
\gamma=0.069 ; \alpha=0.622 ; \delta=0.167 .
$$

We took up in (1) $h=1$ supposing that its real value will be based on the assessed value of normalizing multiplier/factor $\gamma$. In Figure 1 you can see the trajectory of the US GDP calculated on the basis of PF (1) with certain values of constant parameters (4) together with a factual trajectory. As shown in the figure, there is a perfect coincidence in each of the stages. Besides, mean square error of approximation did not exceed $0.05 \%$.

Thus, PF (1) may be successfully employed in long-term forecasting of the trajectory of economic growth in case when there are reliable long-term forecasts of the dynamics of key growth factors $-K, L$ and $A$. It is necessary to take into account the changes in long-term tendencies in the development of modern economy, which were profoundly explored by a French economist Thomas Piketty [26]. In the $20^{\text {th }}$ century there was a range of empirical regularities corresponding to the process of long economic growth, which are justified in a longterm period, when the results of various economic and financial crises are smoothed. A number of these regularities were first formulated by an American economist Nicholas Kaldor [27], and some of them still remain in force even nowadays. However, some of these empirical regularities do not work anymore, which signals the changes in tendencies in the development of the leading economy of the $21^{\text {st }}$-century.

For our future analysis the following Kaldor's regularities are of special importance:

1) The ratio of physical capital to output is nearly constant, i.e.

$$
\text { a) } K=\sigma_{K} \cdot Y, \sigma_{K}=\text { const ; b) } Y=k_{K} K, k_{K}=\text { const , }
$$

where $\sigma_{K}$ is index of capital intensity; $k_{K}$ is the index of capital productivity; in this connection, $\sigma_{K}=k_{K}^{-1}$;

2) The shares of capital and labour in national income are nearly constant, i.e.

$$
\alpha=\text { const and } 1-\alpha+\delta=\text { const ; }
$$

3) The wages for workers if labour share in GDP is constant grow in proportion to labour productivity i.e.

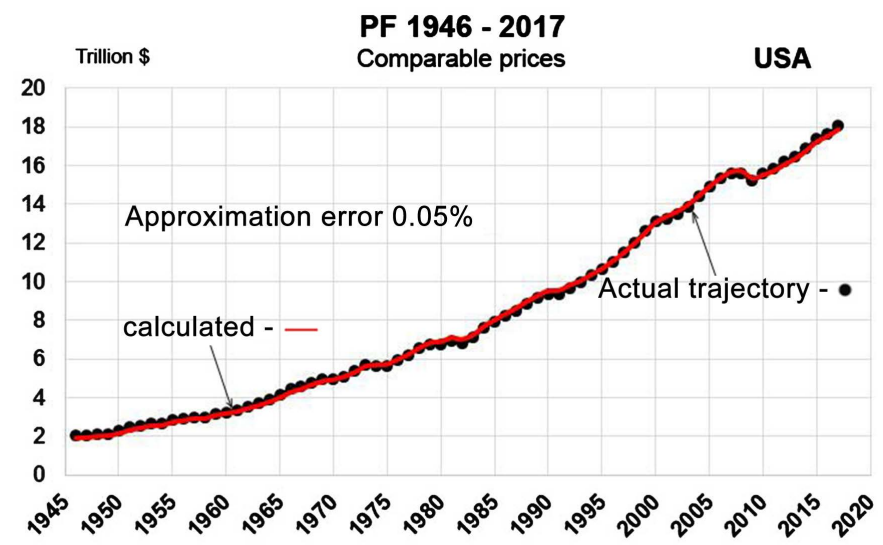

Figure 1. The trajectory of the US GDP movement for the last 70 years. 


$$
\bar{w}(t)=a_{0} \cdot A(t),
$$

where $\bar{w}(t)$ is a current average wage; $a_{0}$ is a normalizing index. Such wage growth was seen in the golden age of the capitalist economy flourishing (19481973).

\subsection{New Empirical Regularities of Economic Development in the First Half of the $21^{\text {st }}$ Century}

The new tendencies of capital accumulation, economic growth, and income inequality emerging at the beginning of the $21^{\text {st }}$ century were comprehensively studied by Thomas Piketty. First of all, Piketty convincingly showed that in the most developed countries (the USA, the UK, Germany, France, etc.) capital intensity $\left(\sigma_{K}\right)$ made a huge $\mathrm{U}$-shaped curve in the $20^{\text {th }}$ century and returned to its maximum values at the beginning of the $21^{\text {st }}$ century, close to those observed at the end of the $19^{\text {th }}$ century ([26], ch.2,3). In the $18^{\text {th }}-19^{\text {th }}$ centuries the value $\sigma_{K}$ in the leading European economies was quite stable and amounted to $\sigma_{K}=7$ in France and the UK, $\sigma_{K}=6.5$ in Germany, and $\sigma_{K}=4.5$ in the USA ([26], ch.3, 4). In the middle of the $20^{\text {th }}$ century the value $\sigma_{K}$ in European countries decreased to a minimum equal to $\sigma_{K}=3.5 \div 3$, and in the USA it stopped at the level of $\sigma_{K}=3.3$. As we can see, changes in capital intensity in the $20^{\text {th }}$-century United States were more limited than in Western European countries, which gave the impression of its stationarity, which was recorded by Kaldor in the first empirical regularity (5).

The return of the value of capital intensity $\sigma_{K}$ in developed countries in the $21^{\text {st }}$ century to its maximum value means that it stabilizes again, at least until the middle of the century ([26], ch.5). Hence, the first empirical regularity of Kaldor (5) remains valid in the first half of the $21^{\text {st }}$ century and will be the determining factor in transformations of PF (1). Our calculations of the value of capital intensity in the US economy for the entire afterwar period (1946-2017), presented in Figure 2 with two graphs (current and comparable prices) show that the US capital intensity remained practically constant throughout the whole period, stabilizing at the beginning of the $21^{\text {st }}$ century around the stationary value

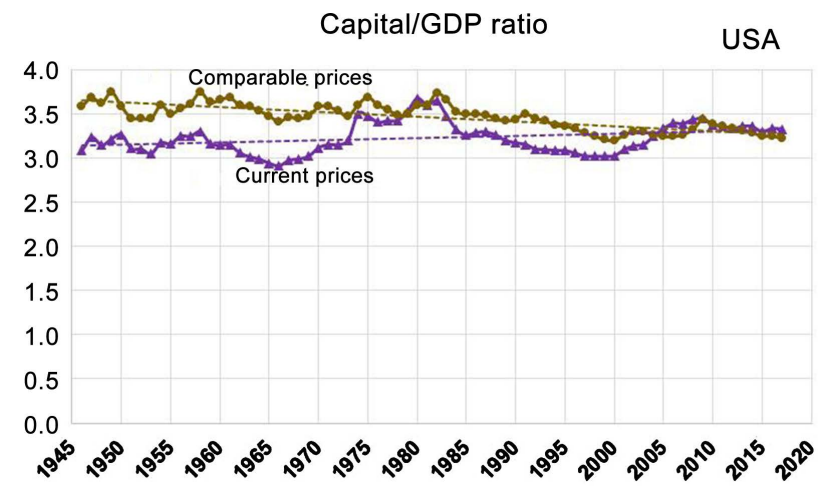

Figure 2. Changes in the value of capital intensity/capital-output ratio $\sigma_{K}$ in the US economy from 1946 to 2017. 


$$
\sigma_{K} \cong 3.3,\left(k_{K}=0.3\right) \text {. }
$$

As for the second empirical regularity of Kaldor (6), in the $21^{\text {st }}$ century it ceases to operate in practice: the share of capital income in GDP $(\alpha)$ will no longer be a constant value, but will grow as Piketty claims [26]. For example, in Western European countries it has already risen from $20 \%-25 \%$, characteristic of the mid- $20^{\text {th }}$ century, to $25 \%-30 \%$ by the beginning of the $21^{\text {st }}$ century. Piketty believes that the share of capital income at the global level will reach $30 \%$ - $40 \%$ by the middle of the century, i.e. the level close to the indicators of the $18^{\text {th }}-19^{\text {th }}$ centuries ([26], ch.6) with average profitability of capital of $4 \%-5 \%$. Such precedents have already taken place in economic history: an increase of 10 percentage points from $35 \%-40 \%$ at the turn of the $18^{\text {th }}-19^{\text {th }}$ centuries up to $45 \%-50 \%$ by the middle of the $19^{\text {th }}$ century. As for the labour share, it fell during such periods accordingly. For example, in the United States, the share of labour in GDP fell from 65\% to 55\% from 1970 to 2015, i.e. in just 45 years. This is exactly what caused the stagnation of worker wages in the United States, which has been observed since the 1970s, instead of their growth in accordance with Equation (7).

\subsection{Mathematical Models for Forecasting the Trajectory of Capital Accumulation in the $21^{\text {st }}$ Century}

Taking into account the new tendencies in the development of leading economies in the $21^{\text {st }}$ century mentioned above, we shall consider models for long-term forecasting of the main factors of economic growth- $K, L$ and $A$. Let us start with capital accumulation. The growth of capital was the most important feature of capitalism in the $19^{\text {th }}$ and $20^{\text {th }}$ centuries. Piketty argues [26] that this process will become more intense in the $21^{\text {st }}$ century. Let us consider the patterns of accumulation of fixed physical capital in the $21^{\text {st }}$ century with the help of the classical equation of capital accumulation ([24], \$2.1):

$$
\dot{K}(t)=I_{K}(t)-\mu_{K} K(t)=s_{K} Y(t)-\mu_{K} K(t),
$$

where $I_{K}(t)$ is production investment, $\mu_{K}$ is the rate of capital outflow, $s_{K}$ is accumulation rate. Here we are talking about the deterioration of infrastructure capital within the framework of one LW. For the US economy during the $5^{\text {th }}$ LW period (1982-2018), we have (1a):

$$
\mu_{K}=0.035 ; s_{K}=0.186 \text {. }
$$

We estimated $\mu_{K}$ value as the regression index in Equation (9) within the $5^{\text {th }}$ LW (1982-2018), and the $s_{K}$ value was taken from the above World Bank database (1a).

Taking into account that the first empirical rule of Kaldor (5) remains valid in the first half of the $21^{\text {st }}$ century, Equation (9) can be rewritten as:

$$
\dot{K}(t)=\left(s_{k} \cdot k_{K}-\mu_{K}\right) K(t) \text {. }
$$

The solution for this equation is exponential capital growth: 


$$
K(t)=K_{0} \cdot \exp \left[\left(s_{K} \cdot k_{K}-\mu_{K}\right)\left(t-T_{0}\right)\right] .
$$

If we take $T_{0}=2018$ as the beginning of the $6^{\text {th }} \mathrm{LW}$ in the US economy, then we find in the World Bank database that $K_{0}=59.3$ trillion US dollars. Taking into account the specific values of the parameters $k_{K}(8), \mu_{K}, s_{K}$ (9a), we find out that $s_{K} \cdot k_{K}-\mu_{K} \cong 0.021$. Thus, under the conditions of the Kaldor empirical regularity (5), in the first half of the $21^{\text {st }}$ century there will be an exponential growth of accumulated capital (11). However, according to the LW theory [17], the effect of capital saturation should happen at its downward stage in the 2040s. Therefore capital accumulation will take place according to a logistic trajectory:

$$
K(t)=K_{1}+\frac{K_{2}}{1+u_{K} \cdot \exp \left[-\vartheta_{K} \cdot\left(t-T_{0}\right)\right]},
$$

where $K_{1}, K_{2}, u_{K}$ and $\vartheta_{K}$ are constant parameters; $T_{0}=2018$. All these parameters are easily determined using the method of least squares only if the exponential trajectory of capital accumulation (11) coincides with the first half of the logistic curve (12), up to the inflection point (2018-2034), which is located in the middle of the $6^{\text {th }}$ LW (2018-2050). Hence, the following estimates are obtained as a result of the calculations for the US economy:

$K_{1}=48.46$ trillion dollars; $K_{1}=105$ trillion dollars; $u_{K}=5 ; \vartheta_{K}=0.1$.

\subsection{Forecast Models for Calculating Potential Workplaces in Digital Economy}

Let us now pass on to the models for predictive calculation of potential workplaces in the economy. There are two possible forecasting options: 1) based on a theoretical model; 2) based on empirical regularities. We shall begin with the first option. Let us take PF (1) as a theoretical model. At the beginning of $\$ 2$ it was verified for the $5^{\text {th }}$ Kondratiev LW (1982-2018) on the example of the US economy and it was shown that the PF can be employed in the long-term forecasting within the $6^{\text {th }}$ Kondratiev LW (2018-2050). We also took up $h \equiv 1$ there. If we now assume that the first Kaldor regularity (5) will be fulfilled, which means balanced economic growth, when $q_{Y}=q_{K}$, then, substituting relation (5в) into PF (1), we obtain the equation for determining the effective amount of labour:

$$
A L=\left(\frac{k_{K}}{\gamma}\right)^{\frac{1}{1-\alpha+\delta}} \cdot K^{\frac{1-\alpha}{1-\alpha+\delta}} .
$$

Solving this equation with respect to $L$, we get the formula for the predictive calculation of workplaces in the economy in terms of its balanced growth:

$$
L_{p t}(t)=\left(\frac{k_{K}}{\gamma}\right)^{\frac{1}{1-\alpha+\delta}} \cdot \frac{1}{A(t)} \cdot K^{\frac{1-\alpha}{1-\alpha+\delta}}(t) .
$$

Thus, according to Formulas (13) and (14), we can carry out a predictive calcu- 
lation of the growth trajectory $A L(13)$, since the predicted trajectory of movement $K(t)$ is already known and is calculated by Formula (12), or of the predicted trajectory of growth of potential workplaces $L_{p t}(t)$ (14) if $A(t)$ is known (see Figure 3). The trajectory of the movement of potential workplaces in the US economy in the digital era $L_{2}(t)$, calculated by Formula (14) with the already known function of technological progress $A(t)$ is shown in Figure 3. As is seen, the number of workplaces is growing until the early 2030s, and then will begin to sharply decline.

Sometimes it is possible to obtain empirical regularities in connection with the creation of new workplaces and the reduction of existing ones, by means of their technological replacement. For example, in the work ([28], ch.3) the authors provide the results of empirical extrapolation forecasting for the next $10-15$ years: a new stage of automation will, on average, reduce $12 \%$ of existing workplaces and create $13 \%$ of new vacancies, which will eventually lead to the creation of 2 million additional workplaces by 2030. This empirical regularity can be most easily approximated by a linear predictive function:

$$
L_{p e}(t)=L_{b d}+\lambda\left(t-T_{b d}\right),
$$

where $L_{b d}$ is the number of employed (workplaces) in the economy in the initial year $\left(T_{b d}=2018\right)$ of the rise of the $6^{\text {th }}$ Kondratiev LW (2018-2050); index $\lambda$ is determined on the condition that in 2030 the number of employed will increase by 2 million workers.

That is why for the US economy, where $L_{b d}=136.6$ million workers, $\lambda=0.17$. The graph of employment growth $L_{1}$ in the US economy in the 2020s and 2030s, calculated with the help of the empirical forecast Formula (15), is shown in Figure 3. Comparing it with the trajectory of actual employment growth during the $5^{\text {th }}$ Kondratiev LW (1982-2018) (see Figure 3), it is clear that during the rise of the digital economy (2018-2040), workplaces will practically be stagnant. The trajectory of employment with balanced economic growth $L_{2}$, calculated using Formula (14) and built on the same Figure 3, also supports the conclusion about the significant technological replacement of workplaces in the digital economy [29].

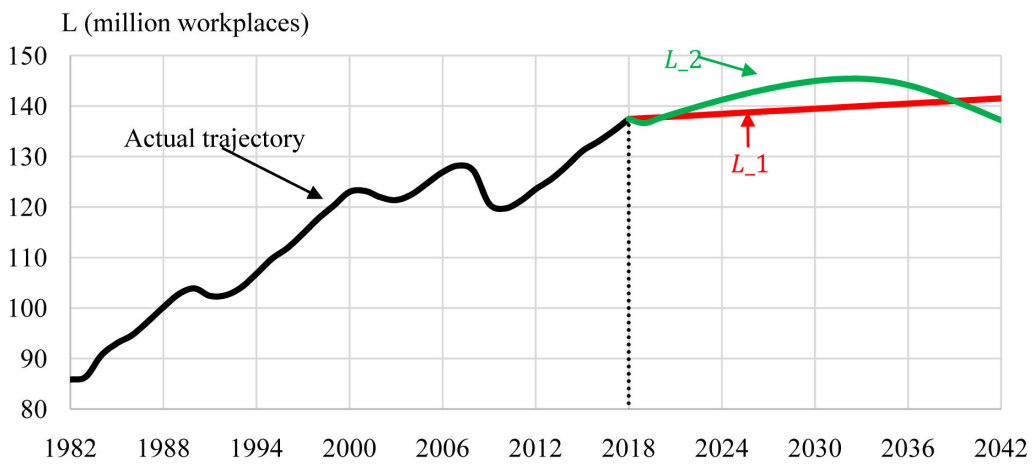

Figure 3. Forecast trajectories of the employment in the US economy according to theoretical $\left(L_{2}\right)$ and empirical $\left(L_{1}\right)$ models. 


\subsection{Forecasting the Trajectory of Economic Growth}

Since from the very beginning we allowed for long-term balanced growth for the economies of developed countries, it is obvious that the forecast trajectory of the GDP movement $Y(t)$ can be calculated using the empirical Kaldor formula $Y=k_{K} \cdot K \quad(5 \mathrm{c})$ through the known forecast trajectories of capital accumulation (11) or more exactly (12). If we take a look only at balanced trajectories of economic growth with effective labour (13), then the forecast trajectory of the GDP movement will naturally be the only one. Such a balanced trajectory of economic growth $Y_{2}$, calculated according to the exponential trajectory of capital accumulation (11) and Formula (5c), is shown in Figure 4. As a comparison, there you can see the forecast trajectory of the GDP movement $Y_{1}(t)$, corresponding to the growth of employment according to the empirical regularity (15) $L_{1}(t)$, calculated on the basis of initial PF (1) with the help of the forecast trajectory of capital accumulation (11) and the known function of technological progress $A(t)$.

Figure 5 shows the projected growth rates of the US economy $q_{1}$ and $q_{2}$ at the upward stage (2018-2042) of the $6^{\text {th }}$ LW (2018-2050), calculated according to the

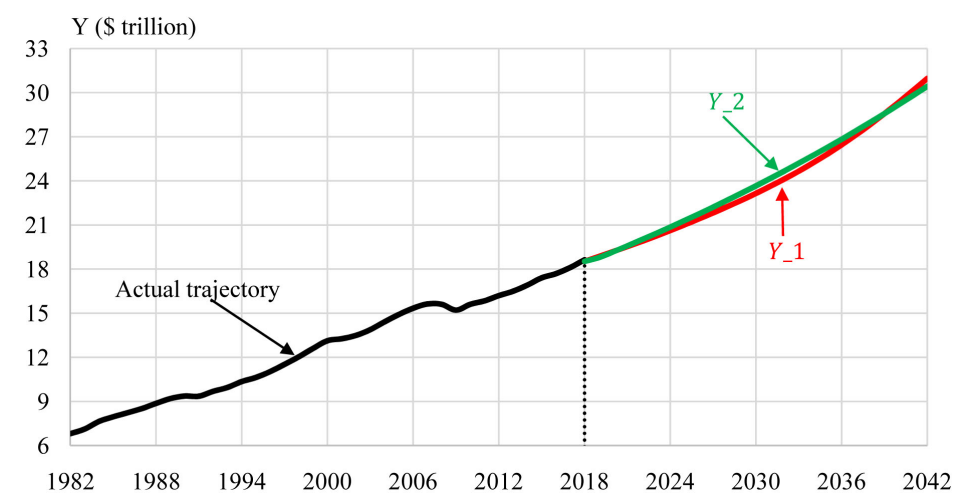

Figure 4. Forecast trajectories of economic growth according to theoretical $\left(Y_{2}\right)$ and empirical $\left(Y_{1}\right)$ models.

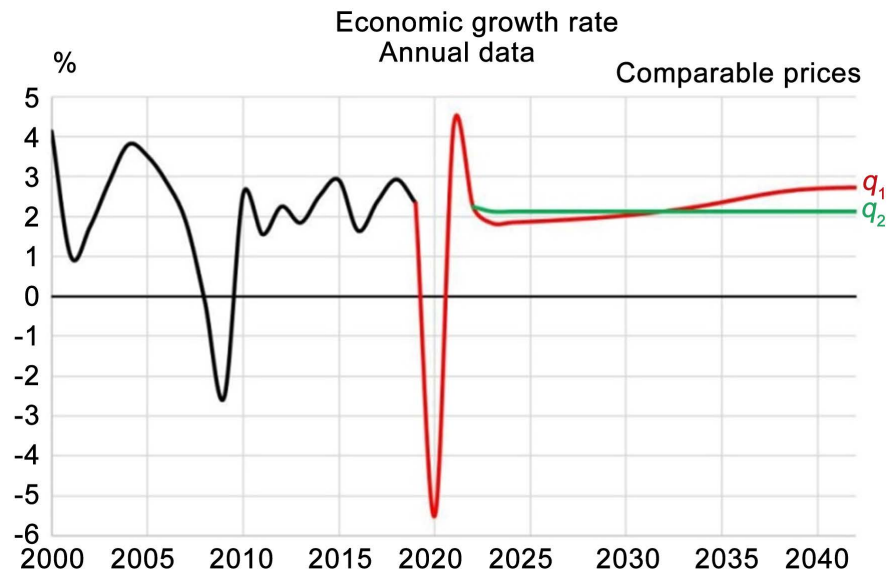

Figure 5. The movement of projected economic growth rates according to theoretical $\left(q_{2}\right)$ and empirical $\left(q_{1}\right)$ models. 
abovementioned forecast trajectories $Y_{1}$ and $Y_{2}$. As can be seen from the graphs $q_{1}(t)$ and $q_{2}(t)$, they make up for about $2 \%$ per year in the next 15 years, as well as in the years of depression (2010-2017), which is directly seen in Figure 5. This was to be expected, since we took into account only technological progress, but did not consider its impact on the productivity of workers. We shall return to this issue later.

Above, we forecasted long-term balanced economic growth using the wellknown Solow neoclassical model in the form of the Cobb-Douglas PF (1). Since the two main factors of growth, capital and labour, can be described using the classical models discussed above, it is now necessary to find a model to be able to reliably forecast technological progress $A_{d}(t)$ in the digital age, which can no longer be described with the help of traditional models. This is explained by the peculiarities of the digital economy and technologies. In the second half of the $20^{\text {th }}$ century technological progress $A(t)$ in the economy was determined mainly by the efficiency of the $\mathrm{R} \& \mathrm{D}$ system. In this regard, various $\mathrm{R} \& \mathrm{D}$ models have been proposed by a number of authors ([24], ch.5). We have developed an improved R \& D equation, invariant to the scale of the economy, which turned out to be very effective and provided a sufficiently accurate solution that allows us to reliably predict both technological progress and long-term economic dynamics [30]. However, in the future digital economy, technological progress will already be determined by the dynamics of the production of technological information. That is why an information formula will be required to determine technological progress, which we obtained in the work [14] and verified for the information age (1980-2018). The mathematical models of economic dynamics and technological progress that are most suitable for the age of the digital economy are given below [25].

The digital economy is a new paradigm for accelerating economic development, improving the quality and usefulness of goods and services. The digital economy is a real developed economy in which a key role is played by digital platforms, platform business models and digital technologies, designed to increase the productivity of economic factors, minimize the costs of materials and resources, and most importantly, improve the accuracy of forecasting demand on the part of consumers and ensure their full compliance with their preferences and requirements regarding the characteristics of goods and services. Therefore, in describing the economic dynamics in the digital age, technological progress, which determines the total productivity of factors, will play a key role, and it is important that it is directly determined by the dynamics of the production of technological information, since the main factors of the digital economy are knowledge and know-how embodied in digital technologies.

\subsection{Mathematical Models for Describing and Forecasting Technological Progress in the Information and Digital Age}

Technological progress $A(t)$, which determines the total productivity of the main economic factors-physical capital $K(t)$ and labour $L(t)$, in the information and 
digital age should naturally depend on the dynamics of production of technological information $S(t)$. Since the rate of economic growth by $80 \%$ or more is determined exactly by technological progress (the total productivity of factors) ([31], ch.1), it is extremely important to establish the desired functional relationship. We shall use the information model first proposed by A. I. Yablonsky ([32], p.163) as a basic model for calculating the rate of technological progress in the information and digital age $q_{A d}(t)$,

$$
q_{A d}(t)=\xi \cdot \frac{I_{d}}{K_{d}} \cdot \frac{\dot{S}_{A d}}{S_{A d}}=\xi \cdot \varepsilon_{d}(t) \cdot q_{s}(t),
$$

where $I_{d}(t)$ is current investment in physical capital $K_{d}(t)$ of the information and digital economy, $S_{A d}(t)$ is a function describing the dynamics of the accumulation of industrial technological knowledge, which determines the advanced technological level in the economy $A_{d}(t) ; \varepsilon_{d}(t)=I_{d} / K_{d}$ is a relative level of investment in the economy, $q_{S}(t)=\dot{S}_{A d} / S_{A d}$ is the growth rate of production technological information in the economy, $\xi$ is a constant calibration index.

Although the ideas underlying the construction of Formula (16) are absolutely correct, however, Formula (16) itself is incorrect, since it does not take into account the correspondence between the dimensions of the right and left sides of the equation. Based on the $\pi$-theorem of the theory of dimensions [33], Formula (16) can be correctly written as:

$$
q_{A d}(t)=\frac{\dot{A}_{d}(t)}{A_{d}(t)}=\xi \sqrt{\frac{I_{d}}{K_{d}} \cdot \frac{\dot{S}_{A d}}{S_{A d}}}=\xi \cdot \sqrt{\varepsilon_{d}(t) \cdot q_{S}(t)} .
$$

Since information and digital technologies are exponentially growing, it can be assumed that $S_{A d}(t)$ will also be an exponential function. Indeed, we have defined (for more details see [25]) that the $S_{A d}$ function is an exponential function written as

$$
S_{A_{d}}(t)=S_{A_{d 0}} \exp [g(t)] .
$$

The fact that the accumulation of industrial technological knowledge in the information and digital sectors of the economy occurs according to the exponential law was previously noted by Raymond Kurzweil ([34], pp. 491-496). Most works usually consider the simplest version of the function, when $g(t)=g_{0} t$ and $g_{0}=$ const, i.e. the case of a linear function. In this paper, we consider the general case when $g(t)$ is a nonlinear but differentiable function. Hence,

$$
\dot{S}_{A_{d}}(t)=S_{A_{d 0}} \cdot \dot{g}(t) \cdot \exp g(t) .
$$

If we substitute representations (19) and (18) into Formula (17), we get a compact formula for calculating the required growth rates of technological progress:

$$
q_{A d}(t)=\xi \sqrt{\varepsilon_{d}(t) \dot{g}(t)} .
$$

Thus, rates $q_{A d}$ of technological progress, which determine the dynamics of the total productivity growth of the main economic factors, in the information 
and digital age will mainly depend on the rates of production of technological information

$$
q_{S_{A_{d}}}(t)=\frac{\dot{S}_{A_{d}}(t)}{S_{A_{d}}(t)}=\dot{g}(t) .
$$

If we know $q_{A d}(t)$, it is quite easy to calculate the trajectory of the technological progress $A_{d}(t)$. itself. Indeed, it follows from Equation (17) that

$$
A_{d}(t)=A_{d 0} \exp \left[\int_{0}^{t} q_{A_{d}}(\tau) \mathrm{d} \tau\right] .
$$

If we put here the expression for $q_{A d}(20)$, we will finally have:

$$
A_{d}(t)=A_{d 0} \exp \left[\xi \int_{0}^{t} \sqrt{\varepsilon_{d}(\tau) \dot{g}(\tau) \mathrm{d} \tau}\right] .
$$

In the work [14] we considered a number of real dynamical regimes of production of technological information. When we derive the equations for the production of technological information, we use the "principle of the minimum production of entropy in self-organization processes" formulated by Yuri Klimontovich ([35], p.36), which in relation to the digital economy can be reformulated as follows: "The principle of the maximum production of information in self-organization processes on the upward stage of the Kondratiev LW." This means that the economic system at the upward stage produces a maximum of information (goods) thanks to the self-organization of agents and using available resources.

In the mathematical form this means that there exists a certain Lagrangian, the functional of which, in accordance with the Klimontovich principle, takes an extreme value at the upward stage of the Kondratiev LW. The corresponding Lagrange equation generates the required dynamical regime of production of technological information. Let us give here four dynamical regimes of production of technological information that are of greatest interest from the point of view of describing information retrospective and forecasting the digital future.

\subsubsection{The Invariable Dynamical Regime}

Information is produced at a constant growth rate $\dot{g}=v_{0}=$ const . The Lagrange function has the form of

$$
L(\dot{g}, g, t)=\dot{g}^{2} .
$$

The corresponding Lagrange equation

$$
\frac{\mathrm{d}}{\mathrm{d} t} \frac{\partial L}{\partial \dot{g}}-\frac{\partial L}{\partial g}=\ddot{g}=0
$$

has the solution

$$
g(t)=g_{0}+v_{0} t, \quad \dot{g}_{0}=v_{0} .
$$

In this case, $S_{d}(t)=S_{d 0} \exp \left(v_{0} t\right)$. The process of accumulation of industrial technological knowledge occurs according to the simplest exponential law which 
characterizes the steady state within the framework of one Kondratiev long economic cycle-a long wave of economic development lasting for 30 - 40 years, formed under the influence of another technological revolution. The simplest dynamical regime of production of technological information described above was characteristic of the symbiosis "human + computer" at the initial stage of the development of computer technology in the period of the $4^{\text {th }}$ long economic cycle (1946-1982).

\subsubsection{The Dynamical Regime with Aggravation}

Growth rates of information production grow exponentially with its accumulation ([34], p. 492), i.e. $\dot{g} \sim \mathrm{e}^{g}$. The following Lagrangian leads to this regime

$$
L(\dot{g}, g, t)=\dot{g}^{2} \mathrm{e}^{-2 g} .
$$

The corresponding Lagrange equation has the following form: $\ddot{g}=\dot{g}^{2}$. The solution of this equation under initial conditions $g(t=0)=g_{0}$ and $\dot{g}(t=0)=v_{0}$ leads to a hyperbolic increase in growth rates of information production:

$$
\dot{g}(t)=\frac{1}{T_{S}-t} ; \quad g(t)=g_{0}-\ln \left(1-\frac{t}{T_{S}}\right) ; \quad T_{S}=\frac{1}{v_{0}},
$$

where $T_{S}$ is a point of singularity.

Equation (25a) resembles the hyperbolic equation of demographic dynamics, first obtained by Heinz von Foerster, Patricia Mora and Lawrence Amiot [36], with a point of singularity at $T_{S}=2026$. In reality, the explosive demographic growth was replaced with the stabilization dynamical regime-demographic transition [37]. The same happened with the dynamical regime of information production in the $5^{\text {th }}$ LW (1982-2018), when instead of explosive growth (25a), smooth logistic growth was realized. We assume that during the $6^{\text {th }} \mathrm{LW}$ (20182050), the dynamical regime with aggravation is implemented with subsequent stabilization.

\subsubsection{The Dynamical Regime with Stabilization}

This regime is a combination of the dynamical regime with aggravation $\dot{g}$ $\mathrm{e}^{g}$, which is implemented at the initial stage of development, and the invariable dynamical regime $\dot{g}=$ const at the final stage: $\dot{g} \sim \frac{\mathrm{e}^{g}}{1+\mathrm{e}^{g}}$.

The Lagrangian has the form of

$$
L(\dot{g}, g, t)=\frac{\dot{g}^{2} \mathrm{e}^{-2 g}}{1-\dot{g}},
$$

and Lagrange equation

$$
\ddot{g}=\dot{g}^{2}(1-g) .
$$

Usually the solution needs to be scaled to make it adequate for the problem at hand. This is done by introducing new variables

$$
g=\frac{\bar{g}}{s_{g}} ; t=\frac{\bar{t}}{s_{t}},
$$


where $s_{g}$ and $s_{t}$ are scaled factors.

The scaled solution of the latter Lagrange equation has the form:

a) $\dot{g}(t)=\frac{1}{s_{g}}\left[1+c_{1} \mathrm{e}^{-s_{g} g(t)}\right]^{-1} ; c_{1}=\mathrm{e}^{s_{g} g_{0}}\left(\frac{1}{v_{0}}-1\right)$;

b) $s_{t} \cdot t=s_{g} g(t)-c_{1} \mathrm{e}^{-s_{g} g(t)}+c_{2} ; \quad c_{2}=\frac{1}{v_{0}}-1-s_{g} g_{0}$.

Here, as we can see from Equation (27a), rates of production of technological information monotonically increase according to the logistic law with a variable rate, because, as follows from Equation (27b), $g(t)$ is not a strictly linear function of argument $t$.

This is the dynamical regime of production of technological information which was observed during the $5^{\text {th }}$ LW. Indeed, as can be seen in Figure 6, which shows the graph of the $q_{A d}(t)$ function calculated by Formula (20) with respect to (27), and the curve with points characterizing the actual values of the contribution of ICT to the rates of technical progress [38], they coincide with a high index of determination $\left(R^{2}=0.998\right)$.

\subsubsection{The Aggravation Dynamical Regime with Return to the Stable Level}

In this scenario, at the initial stage, the process will be sharply escalated ( $\dot{g}$ $\mathrm{e}^{g}$ ) and, due to inertia, it skips the stationary mode ( $\dot{g}=$ const ), and then, having reached a certain maximum value $\dot{g}_{m}$, it returns asymptotically to the stable level. This regime can be described by the relation $\dot{g} \sim \frac{\mathrm{e}^{g}}{1+z(g) \mathrm{e}^{g}}$, where $z(g)$ is the deceleration function, which in the simplest case has the form $\mathrm{Z}(g)=1-\frac{1}{1-\rho} \mathrm{e}^{-\rho g}$, where $\rho=\mathrm{const}$ and $\rho \neq 1$, and if $\rho \rightarrow 0$ the dynamical regime with aggravation is obtained, while if $\rho \rightarrow \infty$, it gets to the dynamical regime with stabilization. This regime is produced by the Lagrangian $L(\dot{g}, g, t)=\frac{\dot{g}^{2} \mathrm{e}^{-2 g}}{1-z(g) \dot{g}}$, and the corresponding Lagrange equation has the form of

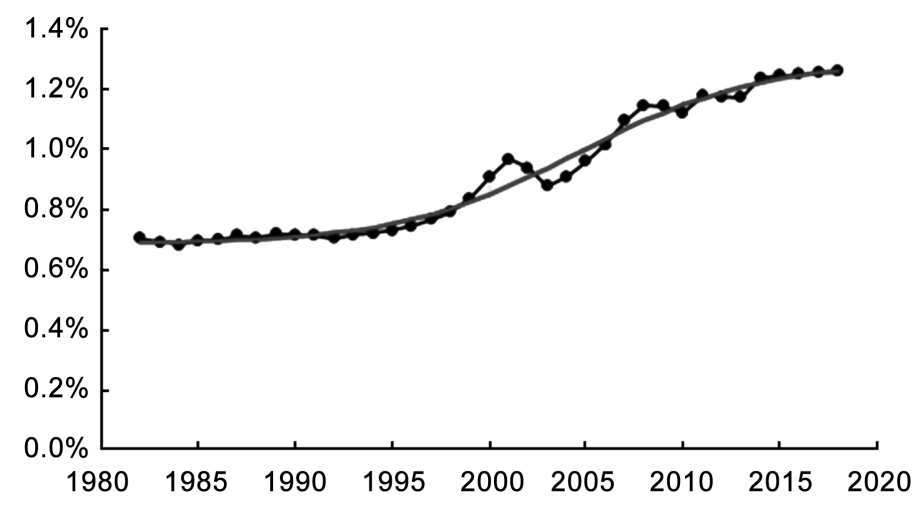

Figure 6. ICT contribution to total labour productivity. 


$$
\ddot{g}=\dot{g}^{2}\left\{1-\dot{g}\left[z(g)+\frac{\mathrm{d} z}{\mathrm{~d} g}\right]\right\} \text {. }
$$

Scaled solution of such an equation has the following form:

a) $\dot{g}(t)=\frac{1}{s_{g}}\left[1-\frac{\mathrm{e}^{-\rho s_{g} g}}{1-\rho}+c_{1} \mathrm{e}^{-s_{g} g}\right]^{-1} ; c_{1}=\mathrm{e}^{s_{g} g_{1}}\left(\frac{1}{v_{1}}-1+\frac{\mathrm{e}^{-s_{g} g_{1}}}{1-\rho}\right)$;

b) $s_{t} \cdot t=s_{g} g+\frac{\mathrm{e}^{-\rho s_{g} g}}{\rho(1-\rho)}-c_{1} \mathrm{e}^{-s_{g} g}+c_{2} ; \quad c_{2}=\frac{1}{v_{1}}-1-s_{g} g_{1}-\frac{1}{\rho} \mathrm{e}^{-\rho s_{g} g_{1}}$.

Here $v_{1}=\dot{g}(t=2018)$ and $g_{1}=g(t=2018)$ are the initial values for the process of production of technological information in the $\sigma^{\text {th }} L W ; s_{g}$ is the scaled factor. It is this scenario of growth with a return according to which the number of population in separate countries is stabilized in the $21^{\text {st }}$ century [39].

Graphs of growth rates of technological information $v(t)=\dot{g}(t)$ described in Equations (27a) and (28a) are shown in Figure 7. All of them are S-shaped curves possessing all the characteristics of the growth curves of technological progress at the upward stage of the LW. Moreover, only $v_{1}(t)$, calculated by Equations (27), is a classical logistic function that asymptotically tends to the stationary level below, while the other two curves $v_{2}\left(\rho_{2}=0.2\right)$ and $v_{3}\left(\rho_{3}=0.1\right)$ avoid the stationary level, due to powerful acceleration, and then, due to the activation of the deceleration mechanism, return asymptotically to the stationary level above. The method of calculating constant parameters and indexes in Equations (27) and (28) will be explained in the following paragraphs. In the next section, by verifying technological progress and economic dynamics at the $5^{\text {th }}$ informational LW (1982-2018), we will show that curve $v_{1}(t)$ allows us to accurately describe the technological progress in the developed economy.

\section{Verification of the Information Model of Technological Progress and Economic Dynamics at the $5^{\text {th }} \mathbf{L W}$ (1982-2018)}

In the previous paragraph $(\$ 2.5)$, mathematical models were given for describing and forecasting technological progress in the age of the information and digital

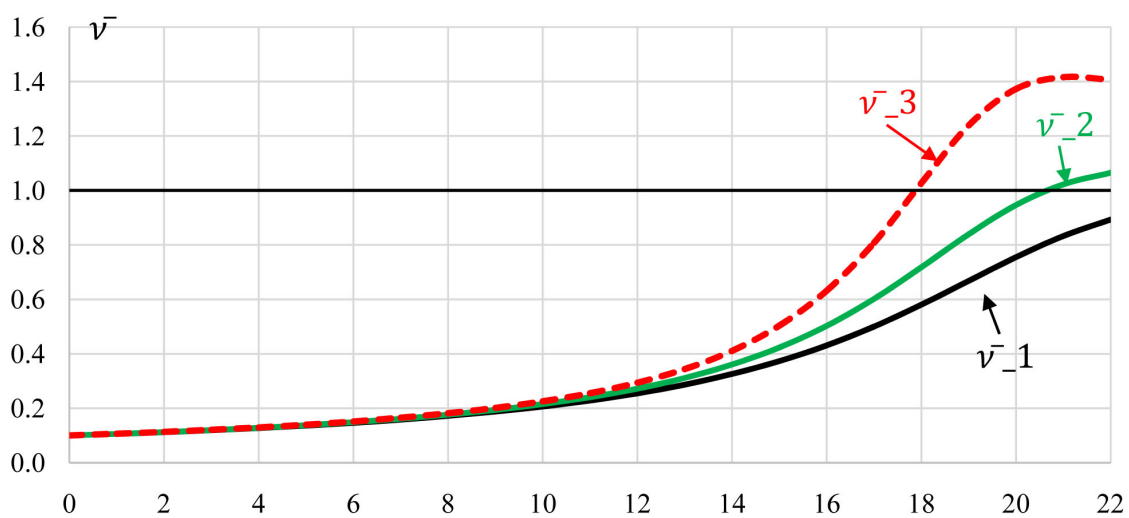

Figure 7. Different trajectories of the growth rates of technological information. 
economy. The models were based on various production regimes of technological information. As a result, they are called information models. The main verified formula is the formula for calculating the growth rates of technological progress (20):

$$
q_{\text {Ad }}(t)=\xi \sqrt{\varepsilon_{d}(t) \cdot \dot{g}(t)},
$$

where $\dot{g}(t)$ is the production rates of technological information in the econo$m y, \varepsilon_{d}(t)$ is relative investments of $I_{d}(t)$ in the fixed productive capital $K_{d}(t)$ of the information and digital economy. Here and in what follows, the normalizing index $\xi$ is assumed to be equal to unity ( $\xi=1$ ), since normalization can be carried out in terms of constant indexes of the function $\dot{g}(t)$. We will verify Formula (29) for the $5^{\text {th }}$ Kondratiev LW in the world economy (19822018), which is characterized as the age of formation of the information economy or the "knowledge economy" in developed countries and for which there exist verified and sufficiently accurate data on both technological progress and economic growth for all OECD countries.

We obtained the actual data on the growth rates of technological progress $\bar{q}_{A d}(t)$ by aggregating the geometric mean series according to the initial data from the two most reliable sources [Bureau of Labor Statistics USA; University of Groningen]. They are presented graphically in Figure 8. In our work [14] an approximate analytical expression was given for approximating $\varepsilon_{d}(t)$ for the US economy:

$$
\varepsilon_{d}(t)=\varepsilon_{0}+\varepsilon_{1}\left(t-T_{0}\right),
$$

where $T_{0}=1982 ; \varepsilon_{0}=0.09 ; \varepsilon_{1}=0.002$. To calculate $\dot{g}(t)$ in the previous paragraph, (\$2.5) the following equations were obtained (27):

a) $v(t)=\dot{g}(t)=\frac{1}{s_{g}}\left[1+c_{1} \cdot \mathrm{e}^{-s_{g} \cdot g(t)}\right]^{-1} ; \quad c_{1}=\left(\frac{1}{s_{g} v_{0}}-1\right) \mathrm{e}^{s_{g} g_{0}}$;

b) $t=\frac{1}{s_{t}}\left[s_{g} \cdot g(t)-c_{1} \cdot \mathrm{e}^{-s_{g} \cdot g(t)}+c_{2}\right] ; \quad c_{2}=\frac{1}{s_{g} v_{0}}-1-s_{g} g_{0}$.

Let us introduce scaled values:

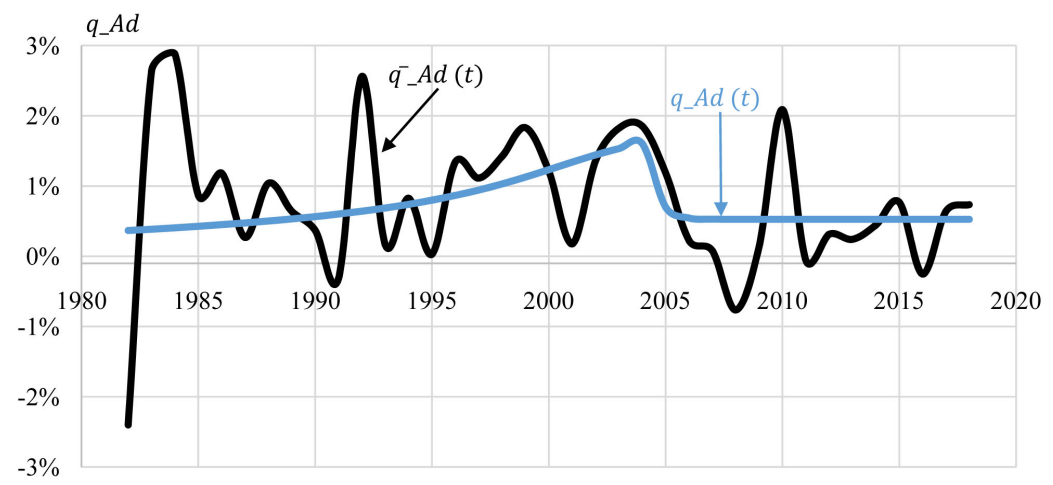

Figure 8. Rates of technological progress according to the information model against the background of the actual curve $\bar{q}_{A d}(t)$. 


$$
\bar{t}=s_{t} \cdot t ; \quad \bar{g}(t)=s_{g} \cdot g(t) ; \quad \dot{\bar{g}}(t)=s_{g} \cdot \dot{g}(t) .
$$

First of all, it is necessary to determine the initial values $g_{0}$ and $v_{0}$, characterizing the production of technological information. To determine $v_{0}$, we use the hyperbolic equation for the growth of rates of information production during the initial period of information technology development (25d), according to which the point of singularity is $T_{s}=v_{0}^{-1}$. It is natural to take 1946 as the beginning of the information age, when the world's first universal computer was put into operation. The explosive growth of the influence of information and communication technologies (ICT) on the economic development of leading countries was first observed in 1995-1997. Therefore, $T_{s} \cong 50$ years and $v_{0}^{\prime}=0.02$ at the initial stage. Yet $g_{0}$ is determined from the solution (25b), assuming that $g_{0}^{\prime}=0$ for 1946 . Then, for the initial year of the upward stage of the $5^{\text {th }}$ LW (1982), from (25b) we get:

$$
\bar{g}_{0}=\ln \left(1-\frac{36}{50}\right) \cong 1.273 .
$$

Next, according to the fact that the logistic function (31a), which describes the production rate of technological information, takes at the beginning of the $5^{\text {th }}$ LW (1982) and at the upper turning point (2004, see Figure 8) the minimum and maximum values, equal to 0.1 and 0.9 respectively, as is generally accepted, we get two equations:

a) $T_{r}=2004 ; \bar{v}_{r}=\dot{\bar{g}}_{r}=0.9=\left\{1+\left(\frac{1}{v_{0}}-1\right) \mathrm{e}^{-\left(\bar{g}_{r}-\bar{g}_{0}\right)}\right\}^{-1}$;

b) $T_{0}=1982 ; \bar{v}_{0}=\dot{\bar{g}}_{0}=0.1=\left\{1+\left(\frac{1}{v_{0}}-1\right) \mathrm{e}^{-\left(\bar{g}_{r}-\bar{g}_{0}\right)}\right\}^{-1}$.

It follows from the second equation that if

$$
T_{0}=1982, \bar{v}_{0}=0.1 \text {. }
$$

From the first equation we get:

$$
T_{r}=2004 ; \bar{g}_{r}=5.67 .
$$

Knowing $\bar{v}_{0}=0.1$ and $\bar{g}_{r}=5.67$, we can calculate numerical values of integration constants $c_{1}$ (31a) and $c_{2}$ (31b):

$$
c_{1}=32.14 ; \quad c_{2}=7.73 \text {. }
$$

Now let us move on to determining the numerical values of the scaled indexes $s_{t}$ and $s_{g}$ (3c). Substituting the expressions for $c_{1}$ (31a) and $c_{2}$ (31b), into Equation (31b), we get the following equation at the upper turning point of the upward wave $\left(T_{r}=2004\right)$ of the $5^{\text {th }} \mathrm{LW}$ :

$$
s_{t}=\frac{1}{T_{r}-T_{0}}\left[\bar{g}_{r}-\bar{g}_{0}+\left(\frac{1}{\bar{v}_{0}}-1\right) e^{-\left(\bar{g}_{r}-\bar{g}_{0}\right)}+\frac{1}{v_{0}}-1\right] .
$$

Substituting here numerical values $T_{r}, T_{0}, \bar{g}_{0}$ (32) and $\bar{g}_{r}$ (33d), we get

$$
s_{t}=0.6 \text {. }
$$


Substituting the expression for the production rate of technological information $\dot{g}(t)$ (31a) and (31b) in Formula (29) we get:

$$
q_{A d}^{(1)}(t)=\sqrt{\frac{\varepsilon_{d}(t)}{s_{g}\left[1+\bar{g}(t)-s_{t} \cdot t+c_{2}\right]}},
$$

where $t=T-T_{0} ; T_{0}=1982 ; T_{0} \leq T \leq T_{r}=2004$. Moreover, here function $\bar{g}(t)$ is in a numerical form by solving the nonlinear Equation (31b) at each point $t$ from a given timespan (37):

$$
s_{t} \cdot t=\bar{g}(t)-c_{1} \cdot \mathrm{e}^{-\bar{g}(t)}+c_{2},
$$

where $\bar{g}_{0} \leq \bar{g}(t) \leq \bar{g}_{r}$.

Since the left side of Equation (37) is set by its actual values, which have already been presented in Figure 8, and only the value of the scaled index $s_{g}$ remained the unknown and undefined on the right side, it can be estimated using the method of least squares. It turned out to be

$$
s_{g}=412.33 \text {. }
$$

Now we can build a trend trajectory of the rates of technological progress by calculating $q_{A d}(t)$ on the right side of Formula (37) with the concrete value $s_{g}=412.33$ (39). The trend trajectory of the rates of technological progress $q_{A d}(t)$ at the upward stage of the $5^{\text {th }}$ LW (1982-2004) is shown in Figure 8.

At the downward stage of the $5^{\text {th }}$ LW (2004-2018), to approximate the trajectory of technological progress, we shall first use the formula for deceleration in technological progress in the recession phase, obtained in the work [17]:

$$
q_{A d}^{(2)}(t)=q_{A d r}^{(1)} \cdot \exp \left\{-\left[1-\lambda_{0}\left(t-T_{r}+\frac{1}{\lambda_{0}}\right) \mathrm{e}^{-\lambda_{0}\left(t-T_{r}\right)}\right]\right\},
$$

where $q_{A d r}^{(1)}$ is the value of $q_{A d}^{(1)}(t)$ (37) at the upper turning point $\left(t=T_{r}\right)$ $T_{r}=2004$. Using the actual data $\bar{q}_{A d}(t)$ given in Figure 8 in the phases of recession and depression in the $5^{\text {th }} \mathrm{LW}$ (2004-2014) with the help of the method of least squares we get:

$$
\lambda_{0}=2.73 .
$$

The corresponding part of the trend trajectory of technological progress in the phases of recession and depression is also shown in Figure 8 (2004-2014). So, it is necessary to find an approximate analytical description of technological progress in the recovery phase (2014-2018) of the $5^{\text {th }}$ LW, which is best approximated by an exponential curve:

$$
q_{A d}^{(3)}(t)=q_{\text {Ade }}^{(2)} \exp \left[\omega\left(t-T_{r e}\right)\right],
$$

where $q_{\text {Ade }}^{(2)}$ is the value $q_{A d}^{(2)}(40)$ in the lower turning point $\left(T_{r e}=2014\right)$.

Proceeding from actual data $\bar{q}_{A d}(t)$ in the recovery phase (2014-2018, see Figure 8), with the help of the method of least squares we estimated

$$
\omega \cong 0 .
$$

Thus, we approximated the rates of technological progress $q_{A d}(t)$ of the $5^{\text {th }}$ 
LW both at the upward (37) and downward (40) and (41) stages. Now we can calculate the trajectories of both actual and model technological progress $\bar{A}_{d}(t)$ and $A_{d}(t)$ by the formula

$$
A_{d}(t)=A_{d 0} \cdot \exp \left[\int_{T_{0}}^{T} q_{A d}(t) \mathrm{d} t\right] .
$$

The initial value $A_{d 0}$ is calculated by the production function (1) using the method of least squares, so that at the initial timepoint $Y_{0}, K_{0}$ and $L_{0}$ would coincide in their actual values with the best approximation of the formula

$$
A_{d 0}=\frac{1}{L_{0}}\left(\frac{Y_{0}}{\gamma K_{0}^{\alpha}}\right)^{\frac{1}{1-\alpha+\delta}} .
$$

The trajectory of the actual technological progress is obtained by numerical integration (42), using the actual data $\bar{q}_{A d}(t)$ presented in Figure 8. The trajectory of the model technological progress is calculated by the Formula (42) with the sequential use of approximating functions $q_{\text {Ad }}(t)(37),(40)$ and (41). The calculation results are presented graphically in Figure 9, in the form of a growth trajectory of the normalized level of technological progress

$a_{d}(t)=A_{d}(t) / A_{d 0}$. The mean square error turned out to be $\sigma_{A}=1.95 \%$. As we can see, the proposed information model of technological progress (29) provides a sufficiently high accuracy of approximation.

Now let us consider how this model error can affect the further calculations of the trajectory of economic growth by the production function (1):

$$
Y(t)=\gamma K^{\alpha}(t)[A(t) \cdot L(t)]^{1-\alpha+\delta} .
$$

Here we have just calculated and verified $A_{d}(t)$ with high accuracy, with a mean square error not exceeding $2 \%$, over a time span of 36 years. The actual data for the main economic variables $Y(t), K(t)$ and $L(t)$ for the US economy were taken from sources (1a). First, the optimal values of the production function parameters (44) $\gamma, \alpha$ and $\delta$ were calculated:

a) At current prices: $\gamma=0.04 ; \alpha=0.73 ; \delta=0.33$

b) At comparable prices: $\gamma=0.07 ; \alpha=0.63 ; \delta=0.19$.

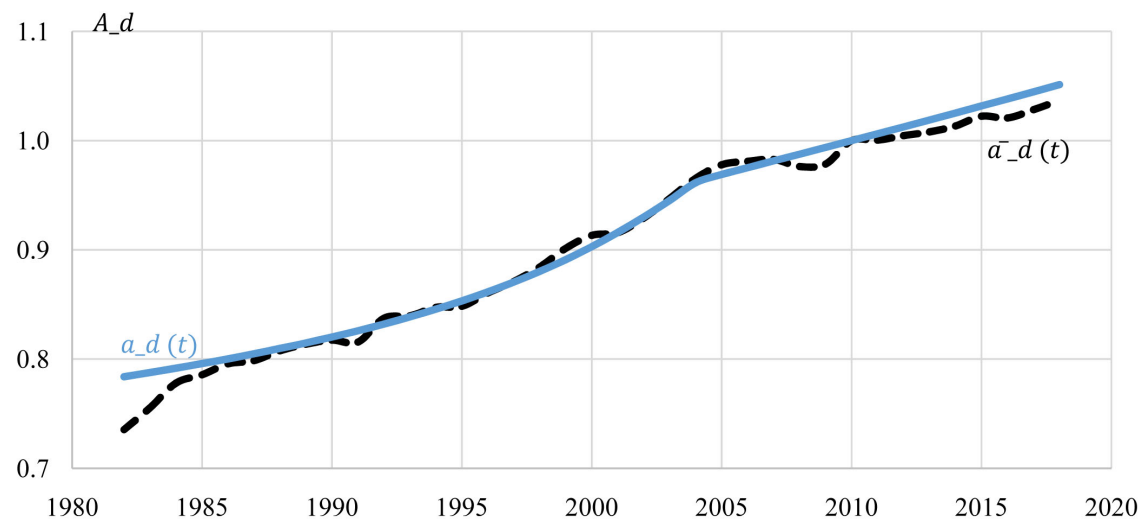

Figure 9. Technological progress in the information age. 
After having calculated these both variants, we obtained a mean square error at current prices $\sigma_{Y}^{(1)}=0.3 \%$ and at comparable prices $\sigma_{Y}^{(2)}=0.13 \%$. The trajectories of economic growth are shown in Figure 10 and Figure 11 respectively.

As can be seen from the graphs in Figure 10 and Figure 11, the accuracy of model (49) in calculating the trajectory of economic growth is much higher than for calculating technological progress, and the accuracy is two times higher for calculating economic growth in comparable prices than in current prices. Therefore, forecast calculations are also recommended to be carried out at comparable prices.

In conclusion, let us calculate the growth trajectory of the production of technological information $g(t)$ from Formula (40):

$$
g(t)=g_{0}+s_{t} \cdot \int_{T_{0}}^{T} \frac{q_{A d}^{2}(t)}{\varepsilon_{d}(t)} \mathrm{d} t, \quad T_{0} \leq T \leq T_{b d}
$$

$$
T_{0}=1982 ; T_{b d}=2018 ; \quad g_{0}=\frac{\bar{g}_{0}}{s_{g}} ; \bar{g}_{0}=1.27 ; s_{g}=412.33 ; s_{t}=0.6 \text {. }
$$

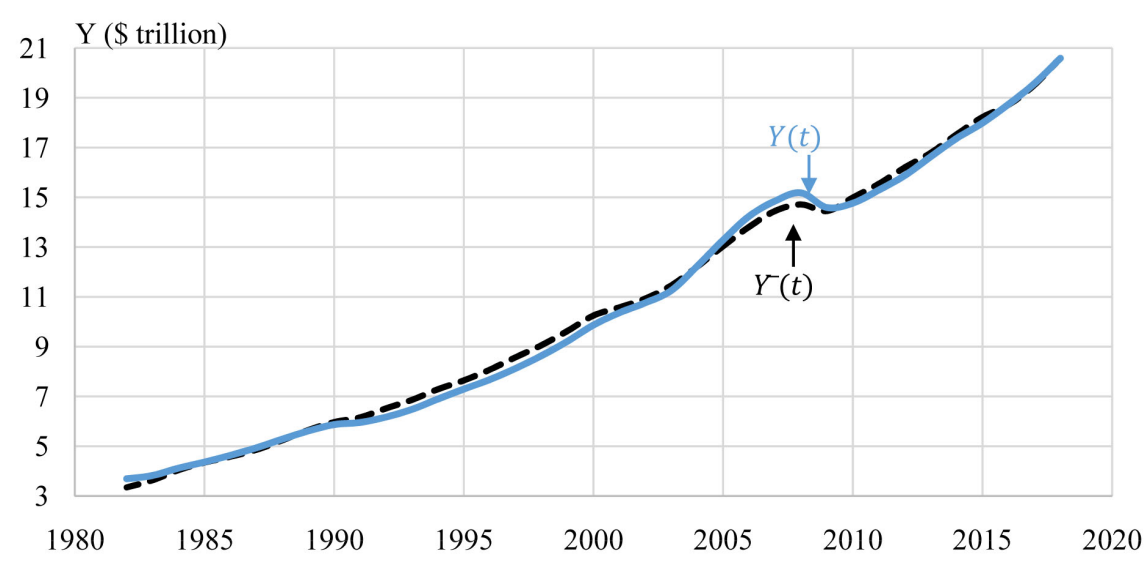

Figure 10. Verification of the calculated trajectory of the US GDP movement (at current prices). A mean square error $\sigma_{Y}=0.298 \%$.

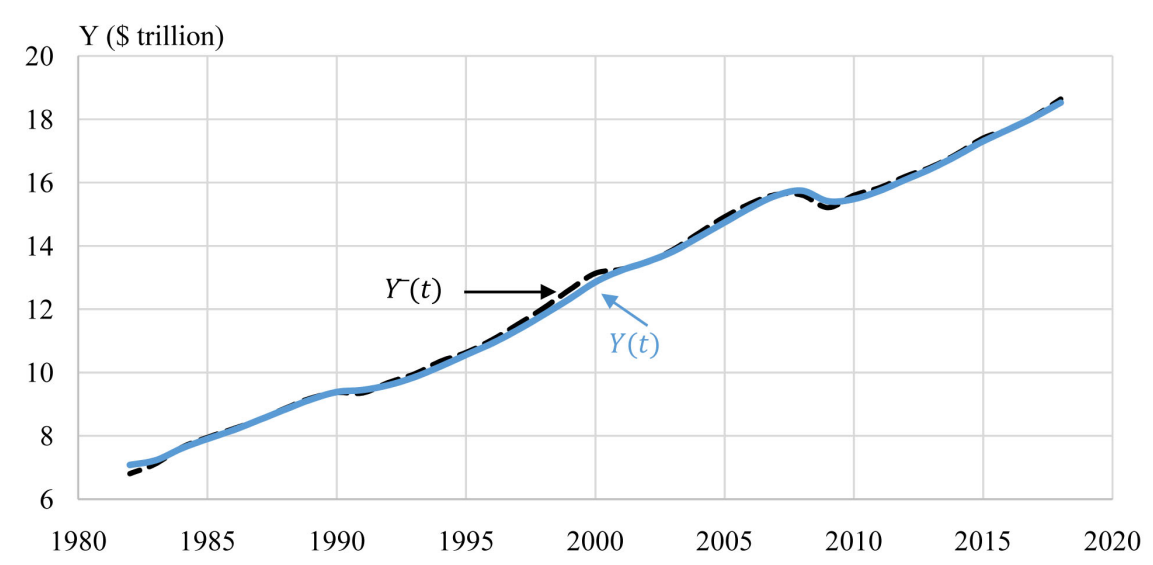

Figure 11. Verification of the calculated trajectory of the US GDP movement (at comparable prices). A mean square error $\sigma_{Y}=0.133 \%$. 
Here, in the integrand, we successively use approximating functions (37), (40) and (41). As a result of calculations, we get the trajectory $g(t)$ shown in Figure 12. As we can see from a comparison of the trajectories $g(t)$ (Figure 12) and $q_{A d}(t)$ (Figure 8), the growth rate of the production of technological information should significantly surpass the rates of technological progress. As was expected, the production growth of technological information is an entirely increasing function and its maximum value at the end point $T_{b d}=2018$ calculated by Formula (69) is

$$
g_{b d} \cong 0.016 \text { or } \bar{g}_{b d} \cong 6.6 .
$$

\section{Forecasting the Technological and Economic Dynamics at the Upward Stage of the $6^{\text {th }}$ Kondratiev LW (2018-2042)}

The dynamics of technological progress at the upward stage of the $6^{\text {th }}$ Konrdatiev LW in world economic development is determined by the accelerated production regime of technological information with a return to the stationary Equation (28):
a) $\bar{v}(t)=\dot{\bar{g}}(t)=\left[1-\frac{\mathrm{e}^{-\rho \bar{g}(t)}}{1-\rho}+c_{3} \cdot \mathrm{e}^{-\bar{g}(t)}\right]^{-1} ; \quad c_{3}=\mathrm{e}^{\bar{g}_{b d}}\left(\frac{1}{\bar{v}_{b d}}-1+\frac{\mathrm{e}^{-\rho \bar{g}_{b d}}}{1-\rho}\right)$;
b) $\bar{t}=\bar{g}(t)+\frac{\mathrm{e}^{-\rho \bar{g}(t)}}{\rho(1-\rho)}-c_{3} \cdot \mathrm{e}^{-\bar{g}(t)}+c_{4} ; \quad c_{4}=\frac{1}{\bar{v}_{b d}}-1-\bar{g}_{b d}-\frac{\mathrm{e}^{\rho \bar{g}_{b d}}}{\rho}$.

Here $\bar{g}(t)=s_{g} \cdot g(t) ; \bar{t}=s_{t} \cdot t ; \quad \bar{g}_{b d}=\bar{g}\left(t=T_{b d}\right) ; \quad T_{b d}=2018 ; \quad \bar{g}_{b d} \cong 6.6$ (46a); $\rho=0.2$. The scaled factors $s_{t}$ and $s_{g}$ have already been defined for the information age: $s_{t}=0.6$ (36) and $s_{g}=412.33$ (39). They also retain their values in the digital age. Taking into account that at the initial point of the upward stage of the $6^{\text {th }}$ LW $\left(T_{b d}=2018\right)$, the value of the logistic function $\bar{v}(t)$ (47a) should equal $\bar{v}(t)$ (47a) and solving Equation (47a) at this point we make sure that the latter turns into identical equation. Therefore,

$$
\bar{v}_{b d}=0.1 \text {. }
$$

Then we can easily find numerical values of integration constants:

$$
c_{3} \cong 6559.3 ; \quad c_{4} \cong 1.1 \text {. }
$$

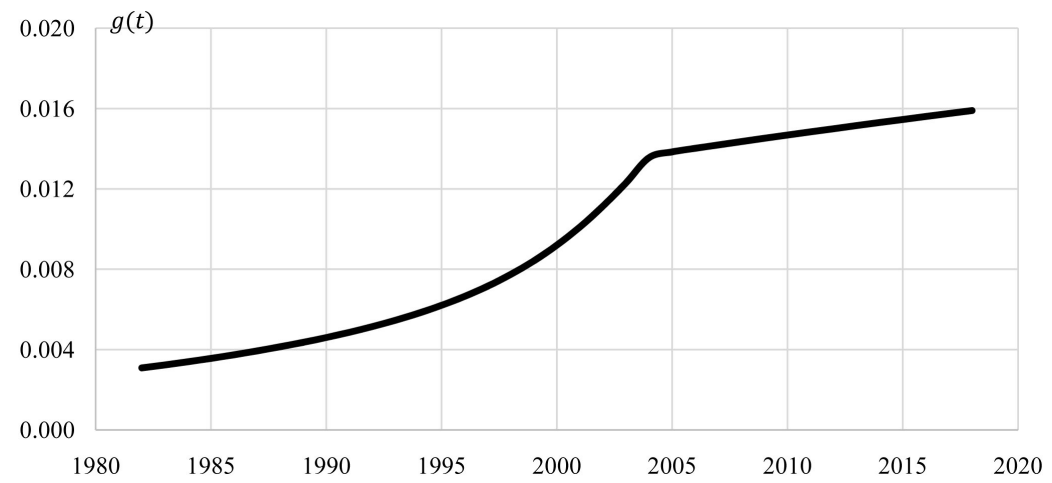

Figure 12. The production growth of technological information in the information age. 
Since the production regime of technological information in question is a regime with a return, the upper turning point of the $6^{\text {th }} \mathrm{LW}$ will be higher than the stationary level, therefore, Equation (47a) at the point of return (return to) $t=T_{r t}$ is reduced to a simplified equation:

$$
\bar{v}_{r t}=\dot{\bar{g}}_{r t}=1.1=\left[1-\frac{\mathrm{e}^{-\rho \bar{g}_{r t}}}{1-\rho}+\left(\frac{1}{\bar{v}_{b d}}-1+\frac{\mathrm{e}^{-\rho \bar{g}_{b d}}}{1-\rho}\right) \mathrm{e}^{-\left(\bar{g}_{r t}-\bar{g}_{b d}\right)}\right]^{-1} .
$$

Here all values except for $\bar{g}_{r t}$ are known. Solving the equation, we find out that

$$
\bar{g}_{r t} \cong 12.72 .
$$

To find the duration of the upward stage of the $6^{\text {th }}$ Kondratiev LW $t_{r t}=T_{r t}-T_{b d}$, we use Equation (47b) at the upper turning point $\left(t=T_{r t}\right)$ :

$$
\bar{t}_{r t}=\bar{g}_{r t}+\frac{\mathrm{e}^{-\rho \bar{g}_{r t}}}{\rho(1-\rho)}-c_{3} \cdot \mathrm{e}^{-\bar{g}_{r t}}+c_{4} \cong 14.3 .
$$

Since the scaled factor is $s_{t}=0.6(36)$, then $t_{r t}=\frac{\bar{t}_{r t}}{s_{t}} \cong 23.8$ years. Therefore, we get

$$
t_{r t} \cong 24 \text { years and } T_{r t}=204 \text {. }
$$

Thus, the duration of the diffusion of digital technologies into the economy is standard for innovative technologies and consists of 24 years. Solving Equation (47b) with the help of the numerical method with respect to $\bar{g}(t)$ in the range $T_{b d} \leq t \leq T_{r t}$, we obtain the numerical values of the function $\bar{g}(t)$, the growth trajectory of which is shown in Figure 13, which is a supplement to Figure 12.

After having determined all the constant parameters and indexes of function $\dot{g}(t)$ (47), describing the production rates of technological information, we can turn to calculating the predicted trajectory of the growth rates of technological progress $q_{A d}(t)$ (29). Substituting the expression for $\dot{g}(t)$ (47) into the original Formula (29) and admitting $\xi=1$, we obtain the following formula for predictive calculations $q_{A d}(t)$ :

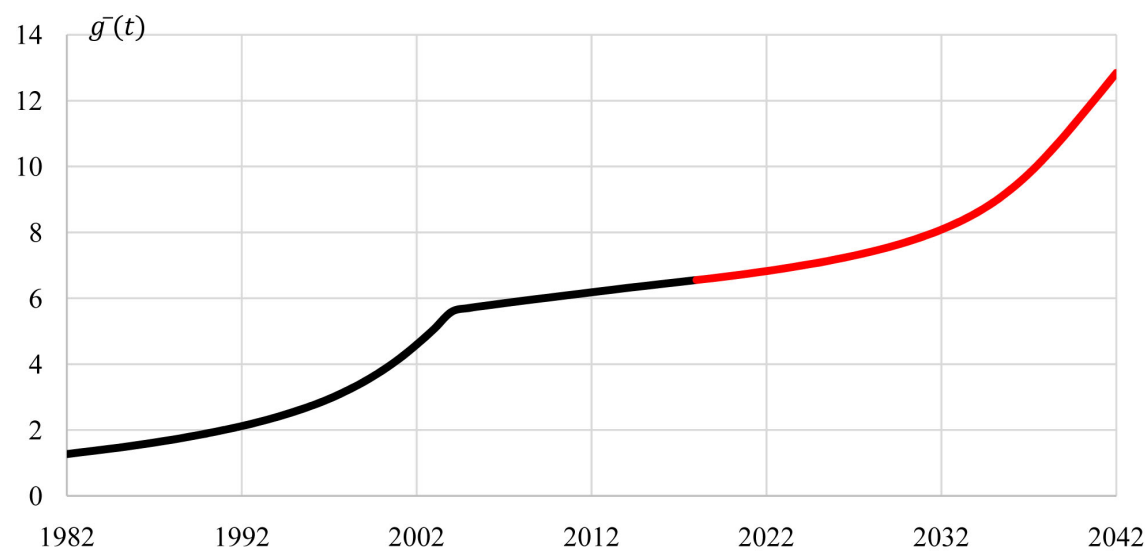

Figure 13. Production growth of technological information in the information and digital age. 


$$
q_{A d}(t)=\sqrt{\frac{\varepsilon_{d}(t)}{s_{g} \cdot\left[1+c_{4}+\bar{g}(t)+\frac{1}{\rho} \mathrm{e}^{-\rho \bar{g}(t)}-s_{t} \cdot t\right]}},
$$

where $t=T-T_{b d}, T_{b d}=2018, \quad T_{b d} \leq T \leq T_{r t}=2042 ; \quad \varepsilon_{d}(t)=\varepsilon_{0}+\varepsilon_{1}\left(T-T_{0}\right)$, $T_{0}=1982, \varepsilon_{0}=0.09, \varepsilon_{1}=0.002$. The forecasted values of the function $\bar{g}(t)$ have already been calculated and presented in a graphical form in Figure 13. The predicted growth rates of technological progress $q_{A d}(t)$, calculated by Formula (50) for the upward stage of the $6^{\text {th }}$ Kondratiev LW (2018-2042) for the US economy, are presented in a graphical form in Figure 14, in addition to the similar indicator in the information age (1982-2018), shown earlier in Figure 8. Next, using Formula (42), we can easily calculate the predicted trajectory of the technological progress $A_{d}(t)$ itself according to the known $q_{A d}(t)$ (50):

$$
A_{d}(t)=A_{b d} \cdot \exp \left[\int_{T_{b d}}^{T} q_{A d}(t) \mathrm{d} t\right] .
$$

Finally, we turn to forecasting the dynamics of economic growth at the upward stage of the $6^{\text {th }}$ Kondratiev LW (2018-2042) using PF (1):

$$
Y(t)=\gamma K^{\alpha}(t)\left[A_{d}(t) L_{p}(t)\right]^{1-\alpha+\delta}
$$

The predicted growth trajectory of technological progress in the digital age $A_{d}(t)$ has already been calculated above (51). Capital accumulation $K(t)$, as was shown earlier, is forecasted by Formulas (11) or (12). Let us choose the simplest exponential law of capital accumulation (11):

$$
K=K_{b d} \cdot \exp \left[0.021\left(T-T_{b d}\right)\right],
$$

where $K_{b d}=59.3$ trillion US dollars; $T_{b d}=2018$.

Employment dynamics is forecasted using Formulas (14) or (15). Let us choose the predictive Formula (15) based on an empirical pattern:

$$
L_{p e}(t)=L_{b d}+\lambda\left(T-T_{b d}\right),
$$

where $L_{b d}=136.6$ million workers, $\lambda=0.17$. Constant parameters $\alpha$ and $\delta$ and a normalized index $\gamma$ have already been given (45b).

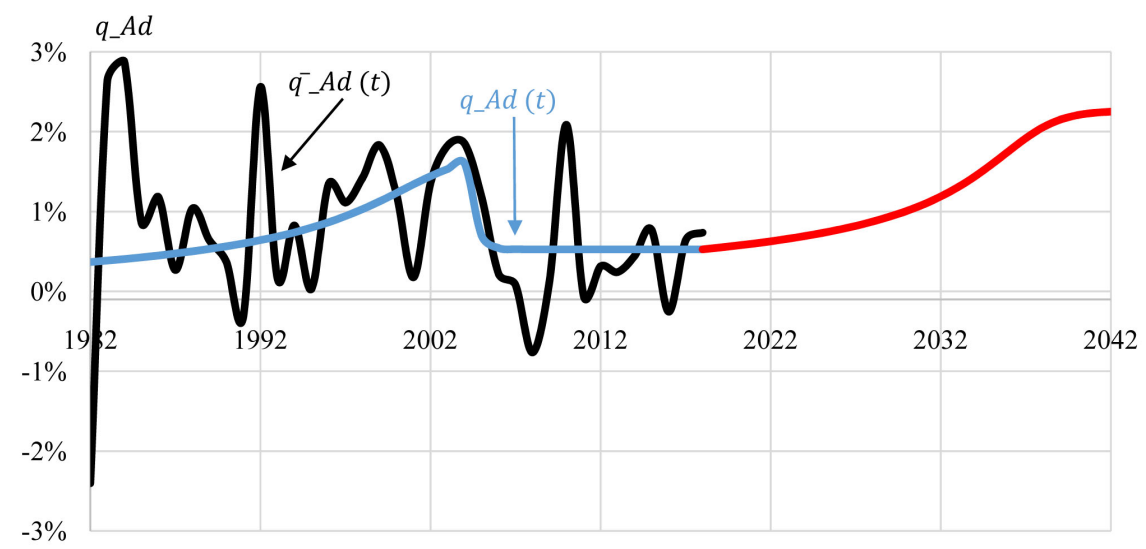

Figure 14. Growth rates of technological progress in the information and digital age. 
In Figure 15 you can see the trajectory of the US GDP, calculated using PF (52) based on the predicted trajectories of the main growth factors $A_{d}$ (51), $K$ (53) and $L_{p e}$ (54) with constant parameters (45b) at the upward stage of the $6^{\text {th }}$ LW (2018-2042). As is shown here, there is an inertial economic growth, continuing the growth trend that developed during the depression years (2010-2016) after the Great Recession of 2009, although digital technologies are expected to provide a significant acceleration. However, we have not yet considered the possible increase in labour productivity through the effective use of the symbiosis "human + intelligent machine".

\subsection{The Main Driving Force of the Digital Economy-The Symbiosis "Human + IM"}

There are enough reasons to believe that most of the work in the future cannot be done without humans. Indeed, any cognitive work can be fragmented into a certain set of tasks, some of which are programmable, and therefore can be automated and transferred for the execution by the IM or bot programmes, while others, in fact, cannot be automated and people will fulfill them. Moreover, the latter, as noted above, are likely to be supplemented and expanded. The book cited above [28] gives the results of special studies indicating that in many cases about $20 \%$ of routine tasks will go to the IM. In general, the dispersion covers from $25 \%$ to $50 \%$. Thus, it is concluded that the upcoming digital automation would take away from people a maximum of $25 \%-50 \%$ of routine and boring work ([28], ch.3). On the other hand, by freeing themselves from such work, humans can redouble efforts to do the rest of the work and significantly increase labour productivity or the quality of performance. These considerations mentioned above will form the basis of our mathematical model for calculating the impact of highly qualified human capital on labour productivity in the digital economy.

The abovementioned resembles the processes of fragmentation of industrial production that began in the 1980s and the transfer of some of them, usually the most labour-intensive, to developing countries with relatively cheap labour. Of course, a progressive step on the part of developed countries was that the process

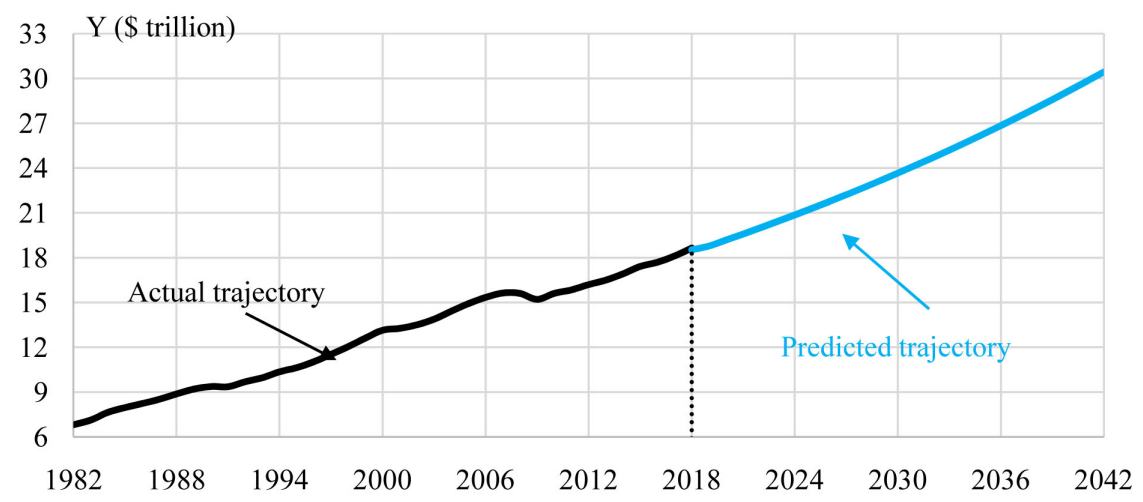

Figure 15. The trajectory of the US GDP movement in the information and digital age. 
was accompanied by the transfer of innovative technologies and know-how, albeit with the aim of ensuring the high-quality standards adopted in developed countries. The correlation of high technologies and low wages drastically reduced the cost of manufacturing products and sharply increased the volume of profits. Good workplaces with high wages, requiring highly skilled workers, remained in the developed countries. Such a situation combined the sources of competitiveness of developed countries-their technological, managerial and marketing know-how-and the comparative advantage of developing countriestheir cheap labour. In the end, everyone won. Moreover, the practice of transferring a labour-intensive routine work from developed to developing countries has convincingly shown that in the end this part of production could be fully automated. In the age of digital intelligent machines, work will be fragmented into tasks, and routine tasks will be transferred to the IM, and an interesting creative part of it will remain for humans. In addition, the overall supervision of any work performance will certainly remain with people. There highly qualified managers will be required.

\subsection{Mathematical Models for Describing and Calculating the Dynamics of Labour Productivity Growth in the Symbiosis "Human + IM"}

As can be seen in Figure 14, technological progress based on digital technologies will grow very slowly in the 2020 s, reaching $1 \%$ by the end of the decade, and only in the 2030s it will significantly accelerate and its rates by the beginning of the 2040 s will double and exceed $2 \%$ per year. However, in the 2020 s it is possible to significantly increase labour productivity in the economy effectively using the symbiosis "human + IM". The main PF (1) contains the value $h$-the level of human capital, which we averaged and equated to unity, shifting its real value to the normalizing factor $\gamma$. In fact, it is a variable, ranging from a minimum value (low skill level) to a maximum (high skill level). With a high level of human capital $h$ (highly qualified employee), it is possible to organize effective joint work of a person and an intelligent machine $\left(A_{d} \cdot h\right)$, which can significantly increase labour productivity in the economy $A_{h}(t)$. Let us show this with the help of a mathematical model.

Labour productivity in the symbiosis "human $+\mathrm{IM}$ " $A_{h}(t)$ in the age of the digital economy can be described by the Equation ([24], ch.6):

$$
\dot{A}_{h}(t)=q_{h}(t) A_{d}^{\beta}(t) \cdot A_{h}^{1-\beta}(t),
$$

where $A_{d}(t)$ is digital technological progress (maximum level of world digital technologies); $q_{h}(t)$ is a function determining the transition process in establishing effective joint work of the human and the IM. Usually this process takes one medium business cycle of $6-10$ years. It can be roughly described with the help of a logistic function:

$$
q_{h}(t)=\frac{q_{h m}}{1+\eta \cdot \exp \left[-\vartheta\left(t-T_{b d}\right)\right]}
$$


If we accept that the duration of a business cycle is 8 years, then the following estimates are easily obtained for parameters $\eta$ and $\vartheta$.

$$
\eta=9 ; \vartheta=0.55 \text {. }
$$

$q_{h m}$ will be estimated later.

Let us consider differential Equation (55) in greater detail. Parameter $\beta$ in this equation characterizes the part of the work that is automated and given to IM, while $(1-\beta)$ is the remaining part of the work that is fulfilled by the human. If $\beta=0$, we obtain the simplest equation from Equation (55)

$$
\dot{A}_{h}(t)=q_{h}(t) A_{h}(t),
$$

which describes the growth of employee productivity without the use of digital technologies and IM. This equation is identical to the one describing the accumulation of human capital $h(t)$ during the years of work after graduation ([40], ch.10.2):

$$
\dot{h}(t)=q_{h}(t) \cdot h(t) .
$$

After graduation a person has some knowledge described by the formula ([24], ch.3):

$$
h=\exp (\psi \cdot u),
$$

where $u$ is an average number of years of study, $\psi$ is the index of return on education. Empirical estimates of this index have shown that $0.06 \leq \psi \leq 0.1$ ([24], ch.3). It means that an additional year of studying increases human capital by 6-10\%. In further calculations we shall use the lower line: $\psi \cong 0.06$. Since in Equation (59) $u \sim t$ during the years of study, then $\dot{h}=\psi \exp (\psi \cdot u)=\psi h$. Hence, it follows that $q_{h m}=\frac{h}{h}=\psi$. Thus, the maximum value $q_{h}(t)$ in Formula (56), on which this function stabilizes, is:

$$
q_{h m}=\psi=0.06 .
$$

When $\beta=1$, then Equation (55) will be:

$$
\dot{A}_{h}(t)=q_{h}(t) A_{d}(t) .
$$

Here, the growth rate of an employee's labour productivity depends solely on digital technological progress, since a person does not participate in work performance, but observes or, at the best, controls the work of IM. For any other values of $0<\beta<1$, Equation (55) shows that labour productivity in the economy grows in proportion to the average weighted quantity of employee's productivity and the level of digital technological progress. In what follows, we shall consider three values of $\beta$ :

$$
\beta_{1}=\frac{1}{3} ; \beta_{2}=\frac{1}{2} \text { and } \beta_{3}=\frac{2}{3}
$$

In the first case fragments of work performed by a person prevail, in the thirdby a machine, while in the second they are equally distributed. It is important for us to know in which of these options we can speak of the maximum labour productivity. 
The solution to Equation (55) has the form:

$$
A_{h}(t)=\left[A_{h 0}^{\beta}+\gamma \int_{T_{b d}}^{T} q_{h}(t) A_{d}^{\beta}(t) \mathrm{d} t\right]^{\frac{1}{\beta}} .
$$

Since the employee's labour productivity at the initial moment $A_{h 0}$ is determined by the human capital accumulated in the learning process (59) and further practice, assuming that a highly qualified person has completed a master's program (who has studied for 18 years or more, i.e. $u=18$ ). Suppose it took an employee 3 years with the highest return $(\psi=0.1)$ to fully master the knowledge and skills of working with IM. Then $u=21$ and if $\psi=0.1$, by Formula (59) we get

$$
A_{h 0}=8.17 \text {. }
$$

Thus, we have obtained Formula (63), which allows us to calculate the dynamics of labour productivity growth in the digital economy for any values of the parameter $\beta$.

In practice, for a comparative analysis, it is not the trajectories of labour productivity growth (63) that are more suitable, but their growth rates $q_{A h}(t)$, which can be most easily obtained from Equation (55):

$$
q_{A h}(t)=\frac{\dot{A}_{h}(t)}{A_{h}(t)}=q_{h}(t)\left(\frac{A_{d}(t)}{A_{h}(t)}\right)^{\beta} .
$$

Substituting the expressions for $A_{d}(t)(51), A_{h}(t)$ (63) and $q_{h}(t)$ in Formula (56), we get:

$$
q_{A h}(t)=\frac{q_{h}(t) \cdot A_{d}^{\beta}(t)}{A_{h 0}^{\beta}+\gamma \int_{T_{b d}}^{T} q_{h}(t) A_{d}^{\beta}(t) \mathrm{d} t}
$$

where

$$
q_{h}(t)=\frac{q_{h m}}{1+\eta \cdot \exp \left[-\vartheta\left(t-T_{b d}\right)\right]} .
$$

Here $A_{h 0}=8.17$ (64); $\eta=9, \vartheta=0.55$ (56a); $q_{h m}=0.06 \quad$ (60).

The growth rates of labour productivity in the digital economy with the widespread and effective use of the symbiosis "human + IM", calculated by Formula (66), are presented graphically in Figure 16 with three values of $\beta$ parameter: $\beta_{1}=\frac{1}{3} ; \quad \beta_{2}=\frac{1}{2} ; \beta_{3}=\frac{2}{3}$. The corresponding curves of labour productivity growth in the digital economy are indicated by the symbols $q_{1}, q_{2}$ and $q_{3}$ (see Figure 16).

As is seen in the growth curves of labour productivity in Figure 16, the highest labour productivity is achieved at $\beta=\frac{1}{3}$, when human labour dominates, and the lowest labour productivity is observed at $\beta=\frac{2}{3}$, when the share of work performed by machines prevails. In any case, we can see that the symbiosis of "human + IM" allows for effective use of the potential of digital technologies at 
the initial stage of the formation of the digital economy, ensuring the growth of labour productivity to potential values already in the mid-2020s (see Figure 16). At the same time, digital technologies are maximally manifested only since the mid-2030s, i.e. a decade later.

If we now use the predictive Formulas (52)-(54) to calculate the trajectory of GDP in the digital era (2018-2042), replacing $A_{d}(t)$ in the production function (52) by $A_{h}(t)$ (63), we get graphs $Y_{1}, Y_{2}$ and $Y_{3}$, shown in Figure 17. As we can see directly from Figure 17, economic growth receives an additional acceleration compared to the basic trajectory of economic growth $\left(Y_{\text {basic }}\right)$. Using these graphs, it is already easy to calculate the rates of economic growth $q_{1}, q_{2}$ and $q_{3}$, which are shown in Figure 18. The graphs of the movement of economic growth rates (see Figure 18) demonstrate that with the effective use of the symbiosis "human + IM" $\left(q_{1}\right)$, the growth rates of the digital economy in the 2020s may confidently exceed 3\% and maintain this level in the 2030s. The US economy has a great chance to grow at a high rate, as in the 2000s, already in the long-term period.

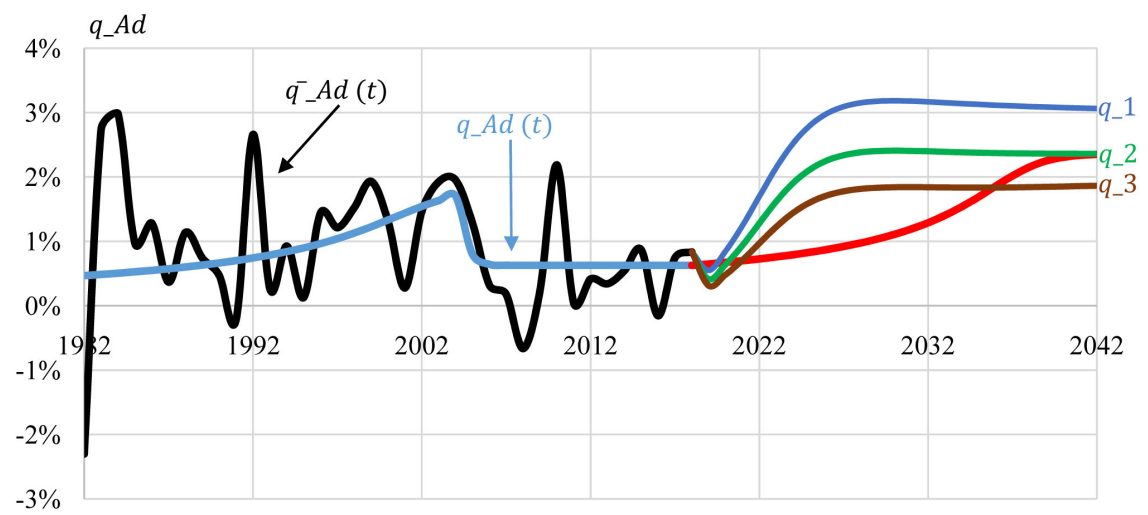

Figure 16. Rates of technological progress in the information and digital age and labour productivity in the digital economy $\left(q_{1}, q_{2}, q_{3}\right)$.

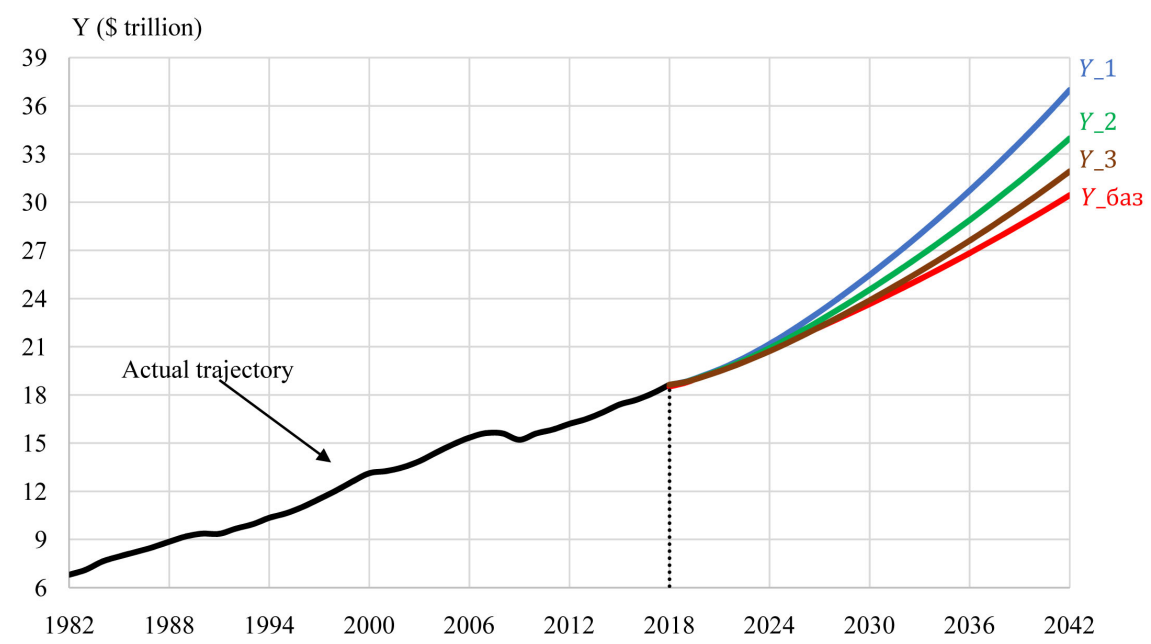

Figure 17. Trajectory of the US GDP movement in the digital age (2018-2042) under different dynamical regimes of the use of the symbiosis "human $+\operatorname{IM}$ " $\left(Y_{1}, Y_{2}, Y_{3}\right)$. 
Economic growth rates

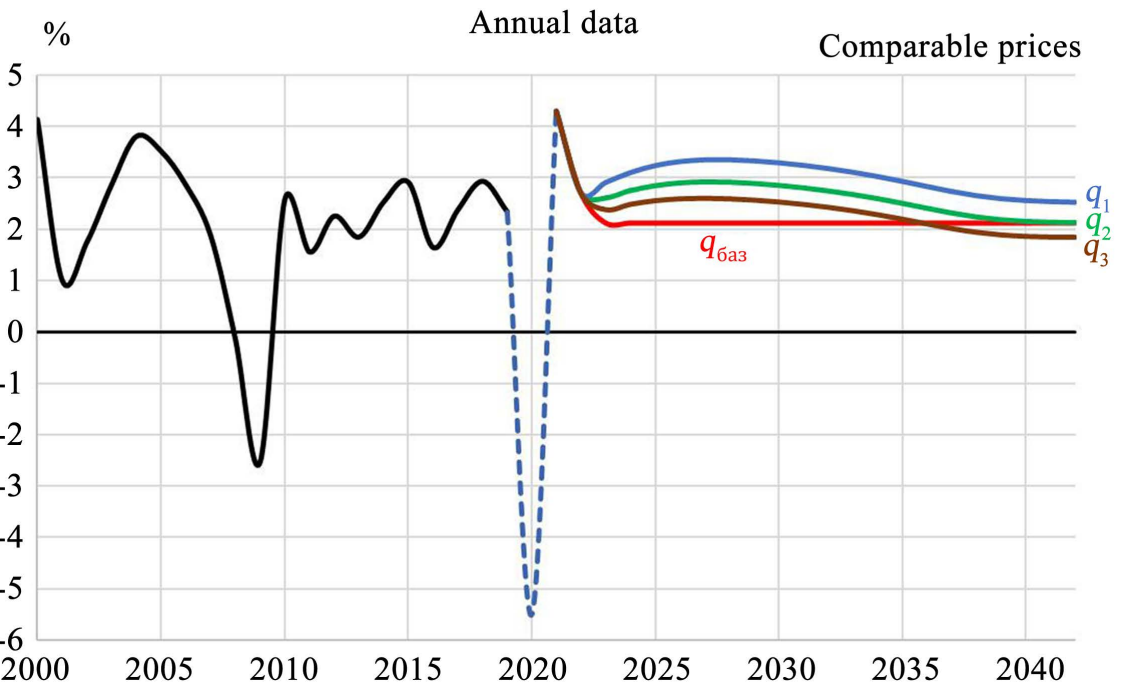

Figure 18. Predicted rates of economic growth $\left(q_{1}, q_{2}, q_{3}\right)$ in the digital age under different dynamical regimes of the use of the symbiosis "human + IM".

\section{Conclusions}

1) For long-term forecasting of technological progress and economic growth, it is more suitable to use the Schumpeter-Kondratiev innovation and cycle theory on the formation of long waves (LW) of economic development, which lasts for about 30 years under the influence of a powerful cluster of innovative technologies generated by cyclically arising industrial revolutions. The Solow neoclassical economic growth model, tied to the LW, makes it possible to accurately predict the economic dynamics of technologically developed countries with the longest forecasting horizon of up to 30 years. Currently, leading countries have entered the upward phase of the $6^{\text {th }}$ LW (2018-2042) under the influence of digital technologies of the $4^{\text {th }}$ Industrial Revolution.

2) In the information and digital age, technological progress plays a key role among the main factors of economic growth (capital, labour and technological progress). The authors have developed an information model which allows for forecasting technological progress basing on growth rates of endogenous technological information in the economy. The main dynamical regimes of producing technological information corresponding to the eras of information and digital economies are highlighted, and the Lagrangians that generate them are constructed. The information model of technological progress was verified on the example of the $5^{\text {th }}$ information LW in the economies of developed countries (1982-2018) for the US economy and was proven highly accurate. High accuracy also occurs when predicting the trajectory of economic growth using an information model for calculating technological progress. It is important to note that forecasts of the accumulation of productive capital and the dynamics of the number of employed in the economy are carried out according to the classical models. 
3) Most of the cognitive work in the digital age will be fulfilled by people, since all of it, as a rule, is fragmented into non-programmable tasks that require creative, highly skilled human labour to solve them, and routine programmable tasks that can be automated and transferred to IM. In this regard, digital competencies and a person's ability to work in a symbiosis with IM are in great demand. All this leads to the inconsistency of numerous predictions and hypotheses that in the digital age, most workplaces will be taken by IM.

4) The main driving force of the digital economy will be the symbiosis "human + IM", which effectively works under the leadership of a person. On the basis of a mathematical model it is shown that, from the very beginning of the formation of the digital economy, precisely due to the high level of human capital and its effective interaction with IM the potential of digital technologies to increase labour productivity is realized. Moreover, it turned out that the highest labour productivity is achieved in the symbiosis "human + IM", where highly skilled human labour dominates, and the lowest labour productivity is observed where the programmed work performed by IM prevails. It is also calculated that for developed economies, which are the leaders in the formation of the digital economy, growth rates of labour productivity equal to $3 \%$ per year can be achieved by the mid-2020s, and it has great chances to remain like this until the 2040s.

5) Since the main driving force of the digital economy is the symbiosis of "human + IM", scholars and developers need to ensure that IM is extremely friendly to people and serve to improve and complement human labour, and enhance its cognitive ability. On the other hand, the education system in the digital age should, along with the formation of deep professional knowledge and solid work skills in people, provide them with good mathematical knowledge, engineering thinking, teamwork skills and sufficient competencies in the field of digital technologies in order to let future specialists successfully and effectively work together with IM.

\section{Conflicts of Interest}

The authors declare no conflicts of interest regarding the publication of this paper.

\section{References}

[1] Organisation for Economic Co-Operation and Development (2014) The Digital Economy, New Business Models and Key Features. In Addressing the Tax Challenges of the Digital Economy, OECD Publishing, Paris.

[2] Inter-American Development Bank (2018) Exponential Disruption in the Digital Economy. Inter-American Development Bank, Washington DC.

[3] Goldfarb, A. and Tucker, C. (2017) Digital Economics. Working Paper No. 23684. National Bureau of Economic Research, Cambridge.

http://pinguet.free.fr/nber23684.pdf

https://doi.org/10.3386/w23684 
[4] International Monetary Fund (2018) Measuring the Digital Economy. Staff Report. International Monetary Fund, Washington DC.

[5] Calvino, F., Criscuolo. C., Marcolini. L. and Squicciarini. M. (2018) A Taxonomy of Digital Intensive Sectors. OECD Science, Technology and Industry Working Papers, No. 2018/14, OECD Publishing, Paris.

[6] Bukht, R. and Heeks, R. (2017) Defining, Conceptualising and Measuring the Digital Economy. International Organisations Research Journal, 13, 143-172. https://doi.org/10.17323/1996-7845-2018-02-07

[7] Jabłoński A. and Jabłoński M. (2020) Social Business Models in the Digital Economy: New Concepts and Contemporary Challenges. Springer Nature.

https://doi.org/10.1007/978-3-030-29732-9

[8] Organisation for Economic Co-Operation and Development (2020) A Roadmap toward a Common Framework for Measuring the Digital Economy.

http://www.oecd.org/sti/roadmap-toward-a-common-framework-for-measuring-th e-digital-economy.pdf

[9] International Federation of Robotics (2017) The Impact of Robots on Productivity, Employment and Jobs: A Positioning Paper by the International Federation of Robotics April 2017.

https://ifr.org/img/office/IFR The Impact of Robots on Employment.pdf

[10] Brynjolfsson, E., Rock, D. and Syverson, C. (2017) Artificial Intelligence and the Modern Productivity Paradox: A Clash of Expectations and Statistics. Working Paper No. 24001. National Bureau of Economic Research, Cambridge.

https://www.nber.org/papers/w24001

https://doi.org/10.3386/w24001

[11] Acemoglu, D. and Restrepo, P. (2018) Artificial Intelligence, Automation and Work. Working Paper No. 24196. National Bureau of Economic Research, Cambridge. https://www.nber.org/system/files/working_papers/w24196/w24196.pdf https://doi.org/10.3386/w24196

[12] Hernandez, K., Faith, B., Prieto Martín, P. and Ramalingam, B. (2016) The Impact of Digital Technology on Economic Growth and Productivity, and Its Implications for Employment and Equality: An Evidence Review. IDS Evidence Report 207, Institute of Development Studies, Brighton.

[13] Solomon, E.M. and van Klyton, A. (2020) The Impact of Digital Technology Usage on Economic Growth in Africa. Utilities Policy, 67, Article ID: 101104.

https://doi.org/10.1016/j.jup.2020.101104

[14] Akaev, A.A. and Sadovnichiy, V.A. (2018) Mathematical Models for Calculating the Development Dynamics in the Era of Digital Economy. Doklady Mathematics, 98, 526-531. https://doi.org/10.1134/S106456241806011X

[15] Kondratiev, N.D. (1935) The Long Waves in Economic Life. Review of Economics and Statistics, 17, 105-115. https://doi.org/10.2307/1928486

[16] Menshikov S.M. and Klimenko L.A. (1989) Long Waves in the Economy. Mezhdunarodnye Otnosheniya, Moscow.[in Russian]

[17] Akaev, A.A. and Sadovnichiy, V.A. (2016) A Closed Dynamic Model to Describe and Calculate the Kondratiev Long Wave of Economic Development. Herald of the Russian Academy of Sciences, 86, 371-383. https://doi.org/10.1134/S1019331616050014

[18] Schumpeter, J.A. (1939) Business Cycles. A Theoretical, Historical and Statistical Analysis of the Capitalist Process. McGraw-Hill Book Company Inc., New York.

[19] Mensch, G. (1979) Stalemate in Technology. Cambridge University Press, Cam- 
bridge.

[20] Hirooka, M. (2006) Innovation Dynamism and Economic Growth. A Nonlinear Perspective. Edward Elgar, Cheltenham, Northampton.

https://doi.org/10.4337/9781845428860

[21] Van Duijn, J.J. (1983) The Long Wave in Economic Life. George Allen and Unwin, London, Boston.

[22] Akaev, A.A., Sadovnichiy, V.A. and Korotaev, A.V. (2011) Huge Rise in Gold and Oil Prices as a Precursor of a Global Financial and Economic Crisis. Doklady Mathematics, 83, 243-246. https://doi.org/10.1134/S1064562411020372

[23] Akaev, A.A. and Rudskoi, A.I. (2015) A Mathematical Model for Predictive Computations of the Synergy Effect of NBIC Technologies and the Evaluation of its Influence on the Economic Growth in the First Half of the 21st Century. Doklady Mathematics, 91, 182-185. https://doi.org/10.1134/S1064562415020209

[24] Jones, Ch.I. and Vollrath, D. (2013) Introduction to Economic Growth. W.W. Norton \& Company, New York, London.

[25] Akaev, A.A. and Sadovnichiy, V.A. (2019) On the Choice of Mathematical Models for Describing the Dynamics of Digital Economy. Differential Equations, 55, 729-738. https://doi.org/10.1134/S0012266119050136

[26] Piketty, T. (2014) Capital in the Twenty First Century. Harvard University Press, Cambridge and London. https://doi.org/10.4159/9780674369542

[27] Kaldor, N. (1961) Capital Accumulation and Economic Growth. In: Hague, D.C., Ed., The Theory of Economic Growth, St. Martin's Press, New York, 177-222. https://doi.org/10.1007/978-1-349-08452-4 10

[28] Frank M., Reohrig P., Pring B. (2017) What to Do When Machines Do Everything. John Wiley \& Sons Inc., New York.

[29] Brynjolfsson, E. and McAfee, A. (2014) The Second Machin Age. W.W. Norton \& Company, New York and London

[30] Akaev, A.A., Sadovnichiy, V.A. and Anufriev, I.E. (2011) Mathematic Models for the Longterm Forecasting of Demographic, Economic, Eco-Energy Development of the World/Problems of Contemporary World Futurology. Cambridge Scholars Publishing, 76-154.

[31] Barro, R.J. and Sala-i-Martin, X. (2004) Economic Growth. MIT Press, London and Cambridge, 2004.

[32] Yablonsky, A.I. (1986) Mathematical Models in Science Research. Mysl, Moscow. [In Russian]

[33] Barenblatt, G.I. (2003) Scaling. Cambridge University Press, Cambridge.

[34] Kurzweil, R. (2005) The Singularity Is Near. Viking Books, New York.

[35] Klimontovich, Y.A. (2019) Introduction to the Physics of Open Systems. Yanus-K, Moscow. [in Russian]

[36] von Foerster, H., Mora, P. and Amiot, L. (1960) Doomsday: Friday, 13 November, A.D. 2026. Science, 132, 1291-1295. https://doi.org/10.4159/9780674369542

[37] Kapitsa, S.P. (2008) An Outline of the Theory of Human Growth. Nikitsky Club, Moscow. [in Russian]

[38] Organisation for Economic Co-Operation and Development (2020) Key ShortTerm Economic Indicators. https://stats.oecd.org/index.aspx?DatasetCode=KEI\#

[39] Akaev, A.A. and Sadovnichiy, V.A. (2010) Mathematical Model of Population Dy- 
namics with the World Population Size Stabilizing about a Stationary Level. Doklady Mathematics, 82, 978-981. https://doi.org/10.1134/S1064562410060360

[40] Acemoglu, D. (2009) Introduction to Modern Economic Growth. Princeton University Press, Princeton, New York. 